\title{
Primary Photochemical Dynamics of Metal Carbonyl Dimers and Clusters in Solution: Insights into the Results of Metal- Metal Bond Cleavage from Ultrafast Spectroscopic Studies
}

\author{
Justin P. Lomont and Charles B. Harris* \\ Department of Chemistry, University of California, Berkeley, California, 94720, and Chemical Science Division, Lawrence Berkeley \\ National Laboratory, Berkeley California, 94720. Corresponding Author: cbharris@berkeley.edu (Phone 15106422814)
}

Supporting Information Placeholder

\begin{abstract}
Metal carbonyl dimers and clusters constitute a diverse class of organometallic reagents and catalysts. The photochemistry of these complexes is a topic of significant and long-standing interest, as preparative-scale photolyses constitute many of the most synthetically powerful reactions in organometallic chemistry. The metal-metal bonding present in dimers and clusters is varied and significantly influences their overall reactivity. In this review we discuss the primary photochemical dynamics of transition metal carbonyl metal dimers and clusters, with a focus on the changes in metal-metal bonding that occur upon visible and/or ultraviolet photochemical excitation. The bulk of the results discussed here were obtained using ultrafast time-resolved infrared spectroscopy, a technique with high structural sensitivity afforded by the carbonyl reporter ligands of the complexes studied. Picosecond time resolution allows detailed monitoring of the photochemical reaction dynamics, including observation of initially excited complexes and short-lived transient metal-metal bond cleavage intermediates, as well as formation of the longer-lived, yet reactive, intermediates responsible for reactivity occurring on diffusion-limited time scales and beyond.
\end{abstract}

KEYWORDS: metal carbonyl dimers, metal carbonyl clusters, photochemistry, metal-metal bonding, time-resolved spectroscopy, infrared spectroscopy

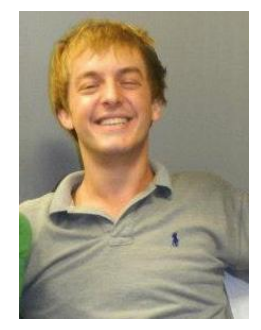

Justin P. Lomont is a $5^{\text {th }}$ year graduate student in Physical Chemistry at the University of California, Berkeley under the direction of Charles B. Harris. He is the recipient of several awards including an NSF Graduate Research Fellowship, an NSF-EAPSI Research Fellowship, and the K. Patricia Cross Future Leaders Award. Justin recently co-authored a book targeted at introducing chemistry to a general audience, and in the future he hopes to become a faculty member at an academic research institution. Upon completing his PhD he has plans to work as postdoctoral fellow with Professor Long Cai at the California Institute of Technology.

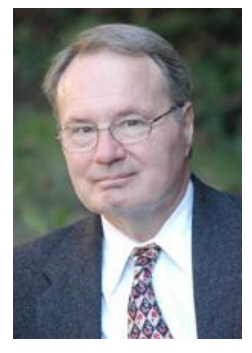

Charles B. Harris received his PhD in Chemistry from the Massachusetts Institute of Technology in 1966 under the direction of Albert F. Cotton. After completing a post-doctoral fellowship in Physics from the Atomic Energy Commission at MIT, he joined the faculty at the University of California, Berkeley, in 1967. He currently holds appointments as a Professor of Chemistry at UC-Berkeley and as a Principle Investigator in the Chemical Sciences Division at Lawrence Berkeley National Laboratory. In addition to his work studying organometallic reaction dynamics using ultrafast infrared spectroscopy, his research also focuses on ultrafast electron dynamics at surfaces and interfaces. He is the recipient of numerous prestigious awards including, most recently, the Ahmed Zewail Award in Ultrafast Science and Technology.

\section{Contents}

1. Introduction

2. Photochemistry of Metal Carbonyl Dimers 
3. Photochemistry of Trimetallic Metal Carbonyl Clusters

Photochemistry of Tetrametallic and Larger Clusters $4.1 \mathrm{Co}_{4}(\mathrm{CO})_{12}$ $4.2 \mathrm{Rh}_{4}(\mathrm{CO})_{12}$ $4.3 \mathrm{Rh}_{6}(\mathrm{CO})_{16}$ 4.4 Comparison of Reactivity 4.5 The Nature of Transient M-M Bond Cleavage Intermediates

\section{INTRODUCTION}

The chemistry of transition metal carbonyl dimers and clusters is a subject of significant and long-standing interest. This is due to their numerous and varied applications in catalysis and as building blocks in the syntheses of organometallic complexes, along with the fact that their chemical reactivity and fluxional rearrangement patterns serve as models for the chemistry of other transition metal cluster complexes. ${ }^{1-3}$ Preparative-scale photolyses are among the most synthetically useful reactions in all of organometallic chemistry, and as such a mechanistic understanding of the elementary steps of the photochemistry behind these reactions carries broad relevance.

The metal-metal (M-M) bonding in these complexes, and in particular the changes in $\mathrm{M}-\mathrm{M}$ bonding that occur upon photoexcitation, play a crucial role in dictating the photochemical reactivity of these species in the solution phase. The 196os represented a renaissance in the theory and experimental observation of $\mathrm{M}-\mathrm{M}$ bonding, with double,${ }^{4}$ triple, ${ }^{5}$ and quadruple ${ }^{6-9}$ bonds all being discovered within the span of just a few short years. At the center of these numerous and rapid discoveries was Albert F. Cotton, to whose fruitful life and career this special issue is dedicated. In addition to his work discovering new types of M-M bonding, Cotton was at the forefront of the initial structural characterizations of many of the complexes studied in this article, laying the foundation for subsequent explorations, such as those described here.

In this article we describe a series of ultrafast investigations into the solution-phase photochemistry of metal carbonyl dimers and clusters, with a focus on the primary photochemical processes involving cleavage of $\mathrm{M}-\mathrm{M}$ bonds. The photochemistry of these complexes is diverse, with excited state lifetimes ranging from femtosecond to millisecond time scales, along with the possibility for charge transfer, ligand dissociation, transient $\mathrm{M}-\mathrm{M}$ bond cleavage, or fragmentation pathways, depending on the identity of the complex and the excitation wavelength used. Initial photochemical cleavage of a M-M bond may result in the formation of long-lived photoproducts that go on to react on diffusion-limited time scales in solution.
Alternatively, M-M bond cleavage may only result in transiently lived intermediates (in which the M-M bond is rapidly reformed), whose short lifetimes preclude their involvement in reactivity occurring on diffusion-limited time scales. In such cases, pathways involving dissociation of a CO ligand are more likely to dictate the bulk solution-phase photochemistry of these dimers and clusters. Knowledge of the solution-phase photochemical behavior of these complexes is quite useful toward reaching a meaningful level of mechanistic understanding of the photochemistry of these dimers and clusters, which can be applied to better understand and predict their synthetic applications.

Here we will largely provide a personal account of work carried out in our research group in recent decades using ultrafast infrared spectroscopy, sometimes in conjunction with other experimental techniques, to characterize the photochemical dynamics of organometallic complexes containing M-M bonds. Most, if not all of the complexes described in this manuscript are widely used, prototypical organometallic reagents whose chemistry can be viewed as a model for a broad range of other organometallic complexes. We have carried out these studies with the hope of being able to offer predictive insight into the reactivity of related complexes whose photochemistry has not yet been directly studied. Where relevant, work occurring in other laboratories will be highlighted and discussed as well. In many cases, computational chemistry has been used in combination with ultrafast spectroscopy to facilitate structural assignments for the species observed experimentally. A number of other excellent reviews and books on this and related topics have been published over the years, and we refer interested readers to some of these publications for additional insight. ${ }^{10-16}$

\section{Photochemistry of Metal Carbonyl Dimers}

\subsection{Cleavage of M-M bonds to Form 17-Electron Radicals}

Some of the earliest studies into the photochemical mechanisms of metal carbonyl dimer reactivity were carried out on the commonly available metal carbonyls of manganese and rhenium $\left(\mathrm{Mn}_{2}(\mathrm{CO})_{10}\right.$ and $\left.\operatorname{Re}_{2}(\mathrm{CO})_{10}\right)$, each of which contain a set of ten terminal $\mathrm{CO}$ ligands and a single 
M-M bond connecting the pair of metal centers. These early studies observed products suggestive of a homolytic cleavage pathway, therefore implying the reactions proceed through 17 -electron (17e) radical intermediates. ${ }^{17-20}$ However, since observation of the products of the reaction provides no guarantee of the mechanism through which they were formed, time-resolved spectroscopic techniques were able to provide more conclusive insight. Nanosecond flash photolysis experiments subsequently confirmed that photochemical excitation of $\mathrm{Mn}_{2}(\mathrm{CO})_{10}$ results in initial homolysis of the M-M bond to yield a pair of $\mathrm{Mn}(\mathrm{CO})_{5}$ radicals. ${ }^{21} \mathrm{~A}$ body of subsequent studies into the photochemistry of other organometallic dimers have since established M-M bond homolysis to be a wide-spread pattern in the primary steps of photochemical reactivity of M$\mathrm{M}$ bonded complexes.

Picosecond time-resolved infrared (TRIR) spectroscopy provides an excellent tool for probing the dynamics of organometallic reactions in real time, as they happen. The experiment involves initial excitation of the parent complex with a femtosecond to picosecond duration visible or ultraviolet pulse, followed by probing of the reaction dynamics via a second ultrafast pulse in the infrared. The infrared spectrum is thus collected at variable time delays between the excitation pulse and the probe pulse, allowing the reaction dynamics to be monitored as a function of time. A TRIR spectrum showing the result of $400 \mathrm{~nm}$ excitation of $\mathrm{Mn}_{2}(\mathrm{CO})_{10}$ at a delay time of $100 \mathrm{ps}$ is plotted in Figure 1. Negative signals (referred to as bleaches) correspond to the species depleted by the excitation pulse, which in this case is the $\mathrm{Mn}_{2}(\mathrm{CO})_{10}$ parent complex. Positive signals correspond to newly formed photoproducts, which in this case are $17 \mathrm{e} \mathrm{Mn}(\mathrm{CO})_{5}$ radicals. The photochemical reaction observed is shown in the inset in the lower left of the TRIR spectrum in Figure 1. This experimental approach is the one most commonly used in our research group to investigate the photochemical reactivity of organometallic complexes, and the majority of the results discussed in this article were obtained from picosecond TRIR experiments.

Assignment of the bleach signals to $\mathrm{Mn}_{2}(\mathrm{CO})_{10}$ can be readily verified by comparison to the FTIR spectrum of the parent complex, while assignment of the bands of $\mathrm{Mn}(\mathrm{CO})_{5}$ can be made, for example, by comparison to infrared bands reported in matrix isolation experiments. ${ }^{22}$ Some of the earliest ultrafast studies into the photochemistry of transition metal dimers also monitored the formation of $17 \mathrm{e}$ radicals from photolysis of $\mathrm{Mn}_{2}(\mathrm{CO})_{10}$ via detection in the visible region of the spectrum. ${ }^{23}$

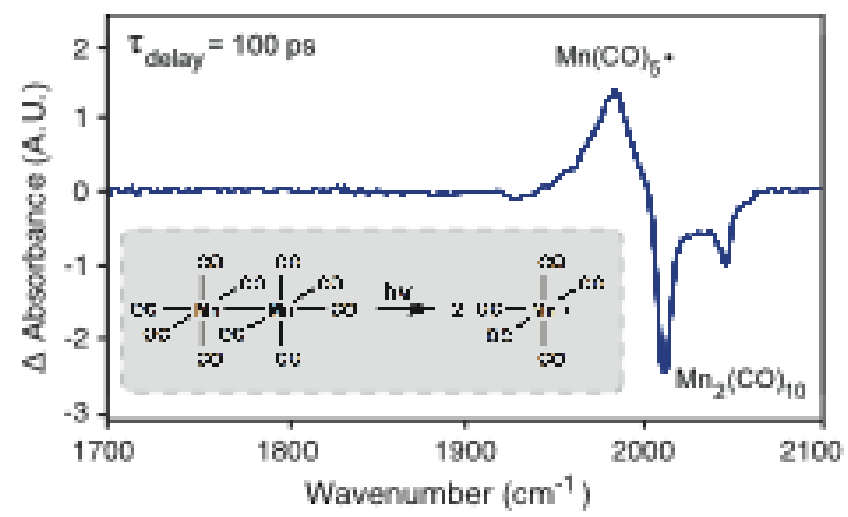

Figure 1. TRIR spectrum of $\mathrm{Mn}_{2}(\mathrm{CO})_{10}$ and its photoproducts observed at a pump-probe delay time of 100 ps following 400 $\mathrm{nm}$ excitation in a mixed solvent consisting of 1:4 molar $\mathrm{P}(\mathrm{OMe})_{3}: \mathrm{CH}_{2} \mathrm{Cl}_{2}$.

In terms of energetics, the typical strength of an Mn$\mathrm{Mn}$ single bond has been estimated at $36 \mathrm{kcal} / \mathrm{mol},{ }^{24}$ while the energies associated with the wavelengths of light used in UV or visible photolysis studies are substantially higher. For example, $267 \mathrm{~nm}$ light corresponds to $107 \mathrm{kcal} / \mathrm{mol}$ of excitation energy, while $400 \mathrm{~nm}$ light corresponds to $71.5 \mathrm{kcal} / \mathrm{mol}$. Of course, bond strengths will vary from complex to complex, especially with the bond order of the M-M bond, but a typical M-M bond enthalpy is thus considerably lower than the energies associated with the wavelengths of light used in UV or visible photolysis studies. M-CO bond enthalpies are also typically only $30-45 \mathrm{kcal} / \mathrm{mol},{ }^{25-27}$ leaving open the possibility for M-CO bond dissociation as a competing or concurrent pathway.

Following dissociation of either type of bond, a significant amount of excess vibrational energy can be expected to be present in the species formed. While this may in principle (and very often in practice) also lead to the dissociation of $\mathrm{CO}$ ligands, visible or ultraviolet photolysis of $\mathrm{Mn}_{2}(\mathrm{CO})_{10}$ in the solution phase leads only to the formation of $17 \mathrm{e}$ radicals via $\mathrm{M}-\mathrm{M}$ bond homolysis. In general the solvent plays a significant role in modulating the photochemistry observed in the solution phase, as evidenced by experiments such as those that demonstrate the cleavage of multiple $\mathrm{M}-\mathrm{CO}$ bonds in the gas phase, but cleavage of only a single $\mathrm{M}-\mathrm{CO}$ bond in the solution phase. ${ }^{28}$ Whereas in the gas phase the excess vibrational energy cannot be readily dissipated into the surroundings, the solvent provides a continuum of phonon modes into which excess energy can be rapidly dissipated, allowing the nascent, excited fragments to thermally equilibrate readily.

\subsection{Geminate Recombination of 17-Electron Radicals}

The photochemical dynamics described in the previous paragraph with regard to $\mathrm{M}-\mathrm{M}$ bond cleavage in $\mathrm{Mn}_{2}(\mathrm{CO})_{10}$ are common to most metal carbonyl dimers. Of interest is the fate of nascent 17e radicals immediately following dissociation of a M-M bond. Essentially there are two possibilities: the 17e radicals may recombine to regenerate the parent dimer (termed geminate recombination), or they may diffuse apart into the bulk solution. Dynamic changes 
in peak intensities observed in the infrared spectrum provide insight into the fate of the 17e radical photoproducts following M-M bond cleavage.

Long ago it was observed that the efficiency for dissociation of $I_{2}$ in the gas phase is lower than that in solution, and, as early as the $1930{ }^{29-31}$ a caging effect due to surrounding solvent molecules was proposed to explain this observation. The advent of ultrafast spectroscopy made it directly possible to observe these dynamics as they occur, and indeed the solvent cage clearly plays a role in the photodissociation of $\mathrm{I}_{2}$. The same holds true for photodissociation reactions generating organometallic radical products. The central notion is that collisions with the surrounding solvent molecules provide an impetus for potentially faster recombination of the nascent radical fragments, lowering the overall efficiency of photodissociation. This has been studied by a number of researchers, both with regard to organometallic dimers, ${ }^{32-37}$ and other classes of molecules. $^{38,39}$

In the solution phase, geminate recombination events may be divided into two classes, termed primary and secondary. Primary geminate recombination is that which occurs prior to diffusion out of the solvent cage, while secondary geminate recombination occurs via diffusive encounters of the reactive fragments through the bulk solution. Another class of dimeric metal carbonyl complexes which have been widely studied are those which contain both $\mathrm{CO}$ and cyclopentadienyl $(\mathrm{Cp})$ ligands. Figure 2 schematically shows these two possibilities for a pair of $\mathrm{CpW}(\mathrm{CO})_{3}$ radicals generated from homolysis of the $\mathrm{W}-\mathrm{W}$ bond in the $\left[\mathrm{CpW}(\mathrm{CO})_{3}\right]_{2}$ dimer.

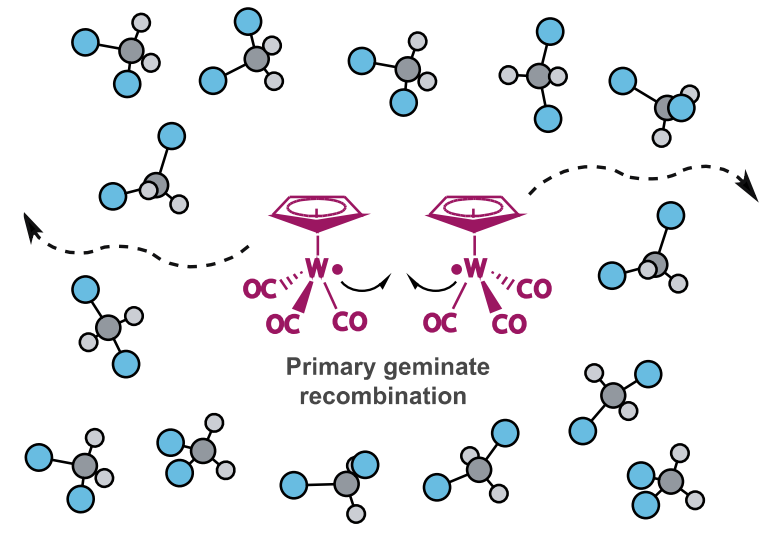

Diffusion out of solvent cage $\rightarrow$

$$
\text { secondary recombination or other reactivity }
$$

Figure 2. Solution-phase photolysis of a transition metal dimer to yield a pair of organometallic radicals can result in either primary geminate recombination or diffusion out of the solvent cage.

Recombination dynamics can be directly observed in TRIR spectra, as the changes in band intensity correlate to increases or decreases in the population of a chemical species. The integrated intensity for an infrared band of a $17 \mathrm{e}$ radical photoproduct can be plotted as a function of delay time to observe its geminate recombination dynamics. Figure 3 shows such a kinetic trace for the radical photo- product $\mathrm{CpW}(\mathrm{CO})_{3}$ generated upon $400 \mathrm{~nm}$ photolysis of the $\left[\mathrm{CpW}(\mathrm{CO})_{3}\right]_{2}$ dimer in neat $\mathrm{CH}_{2} \mathrm{Cl}_{2}$ solution. ${ }^{37}$ The intensity of the infrared absorption corresponding to the $\mathrm{CpW}(\mathrm{CO})_{3}$ radical exhibits a rise time of $4 \pm 2$ ps, corresponding to the time scale of its formation (potentially also influenced by vibrational relaxation), and an initial decay of $52 \pm 16$ ps associated with a ca. $9 \%$ decrease in overall magnitude (the observed dynamics are again potentially influenced by vibrational relaxation). The parent bleach intensities (kinetics not shown) exhibit recovery dynamics on a similar timescale, indicating that the 17 e radicals are recombining to form the parent complex. The magnitude of the parent bleach recovery is potentially more difficult to interpret in terms of a recombination efficiency, since relaxation from non-dissociative excited states also contributes to recovery of the parent bleach signal.

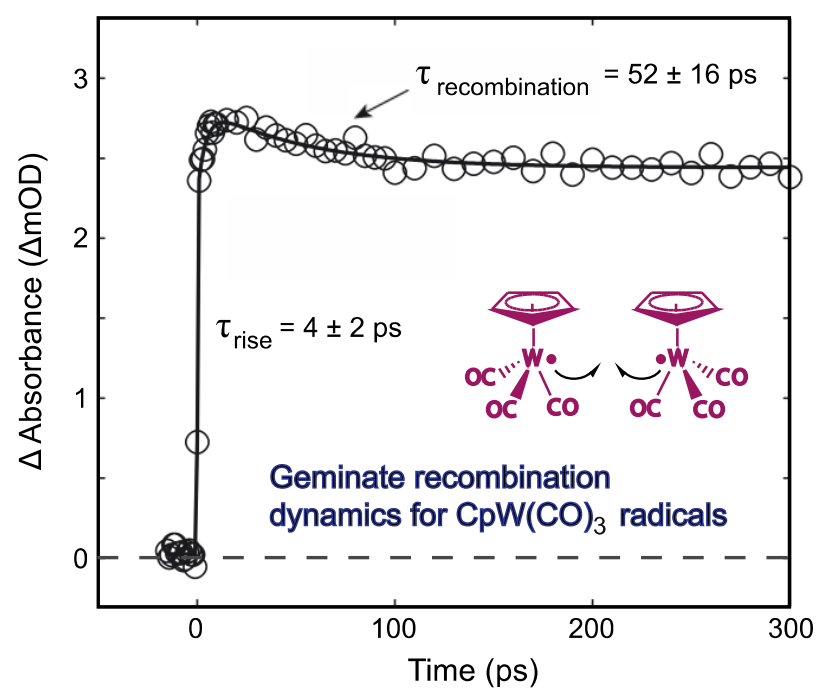

Figure 3. Geminate recombination dynamics of $17 \mathrm{e}$ $\mathrm{CpW}(\mathrm{CO})_{3}$ radicals in $\mathrm{CH}_{2} \mathrm{Cl}_{2}$ solution following $400 \mathrm{~nm}$ photolysis of $\left[\mathrm{CpW}(\mathrm{CO})_{3}\right]_{2}$. Reprinted (adapted) with permission from (J.F. Cahoon, M.F. Kling, S. Schmatz, C.B. Harris, J. Am. Chem. Soc. 127 (2005) 12555.). Copyright (2005) American Chemical Society.

The factors that influence the extent to which solvent caging affects the observed geminate recombination dynamics have been studied in detail by Tyler et al. ${ }^{32}$ Increases in solvent viscosity increase the rebinding efficiency for a nascent radical pair by making it more difficult to rapidly escape the solvent cage. Polarity effects were also examined but determined to be either weak or altogether absent. With regard to the characteristics of the radicals themselves, cage effects were more pronounced with increases in the size of the substituents attached to the $17 \mathrm{e}$ species, and with decreases in the mass of the radicals; the effect of mass has been attributed to their lower momentum upon photodissociation..$^{32}$ Rebinding of the radical pair may be structurally selective with regard to the relative orientation of the molecules, as evidenced by recent transient 2-dimensiontal infrared measurements. ${ }^{40}$ The question of whether a spin barrier influences this has also been investigated, but no evidence was found to support the existence of such a barrier. ${ }^{41}$ 
Radical recombination efficiencies vary widely depending on the variety of factors mentioned above. Changes in solvent viscosity, for example, can tune recombination efficiencies from less than $20 \%$ to greater than $80 \%$ for a given molecule, ${ }^{32}$ and matrix isolation can prevent the observation of any radical products entirely. ${ }^{42}$ Solvent caging effects are now known to play a significant role in both thermal and photochemical reactivity in the solution phase, influencing the CIDNP and magnetic isotope effects, solvent-dependent yields and reaction products, solvent-dependent quantum yields, and correlations between solvent viscosity and reaction rates. ${ }^{32}$ In the next subsection we will look at a reaction mechanism involving nascent pairs of $17 \mathrm{e}$ radicals that occurs within the solvent cage on the ultrafast time scale.

\subsection{Photochemical Disproportionation}

Under appropriate conditions, further reactions involving a pair of nascent 17e radicals may occur prior to diffusion out of the solvent cage and into the bulk solvent. In the presence of a strong Lewis base, such as a phosphine or phosphite, ligand coordination to form a 19-electron (19e) adduct can often take place. Depending on the characteristics of the 19e adduct formed, this species may serve as a strong enough reducing agent to transfer an electron to the nearby 17e radical while the pair remains in close proximity within the solvent cage. Such a reaction yields a pair of 18-electron (18e) disproportionation products. Tyler et al. were among the first to study such reactions involving transition metal dimers on diffusion limited timescales (i.e. occurring after diffusion out of the solvent cage). ${ }^{43-46}$ Subsequent TRIR studies by our group delved further into the mechanistic details, uncovering the "in-cage" disproportionation reaction described in this paragraph (see also top of Figure 4).37,47 Photochemical disproportionation reactions are of significant interest as they represent photoinduced electron transfer reactions.
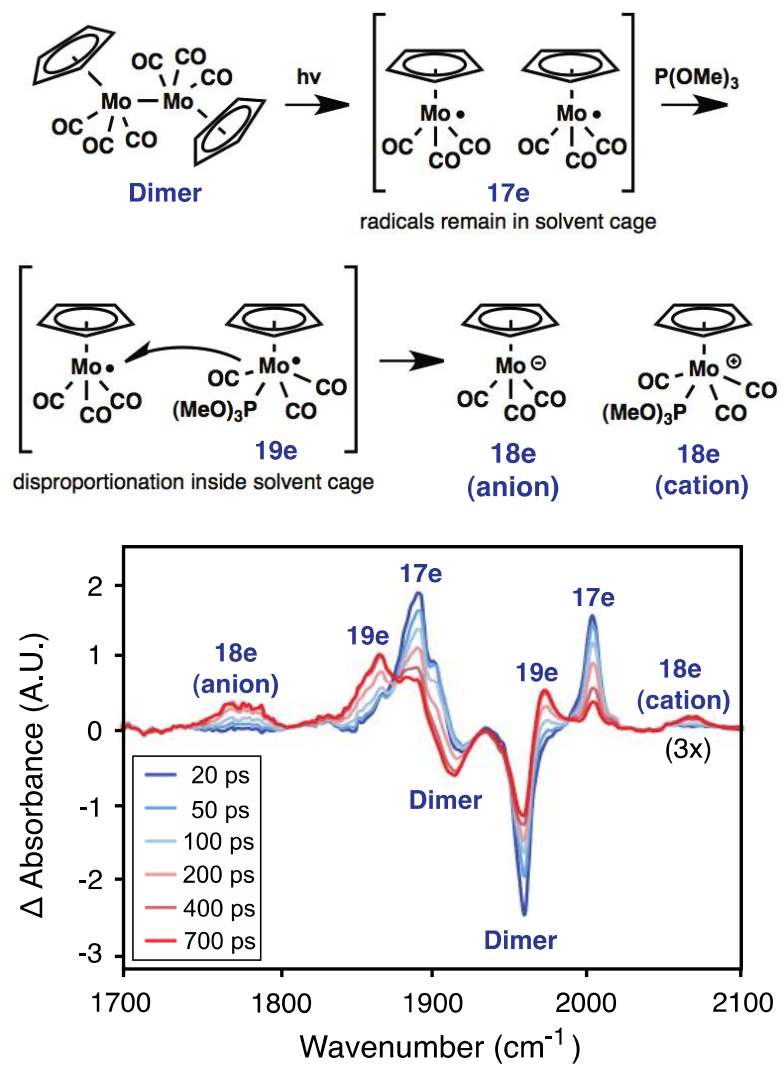

Figure 4. Mechanism (top) and TRIR spectra (bottom) for the photochemical disproportionation of $\left[\mathrm{CpMo}(\mathrm{CO})_{3}\right]_{2}$ in a $1: 4$ molar solution of $\mathrm{P}(\mathrm{OMe})_{3}: \mathrm{CH}_{2} \mathrm{Cl}_{2}$ following $400 \mathrm{~nm}$ photolysis. Incomplete decay of the bands corresponding to the $17 \mathrm{e}$ species $\mathrm{CpMo}(\mathrm{CO})_{3}$ suggest that an equilibrium between this species and the 19e $\mathrm{CpMo}(\mathrm{CO})_{3}\left(\mathrm{P}(\mathrm{OMe})_{3}\right)$ adduct is reached. Reprinted (adapted) with permission from (J.P. Lomont, S.C. Nguyen, C.B. Harris, J. Phys. Chem. A 117 (2013) 3777.). Copyright (2013) American Chemical Society.

Figure 4 shows the mechanism (top) and picosecond TRIR spectra (bottom) for the in-cage disproportion reaction observed upon photolysis of $\left[\mathrm{CpMo}(\mathrm{CO})_{3}\right]_{2}$ in a solvent consisting of 1:4 molar $\mathrm{P}(\mathrm{OMe})_{3}: \mathrm{CH}_{2} \mathrm{Cl}_{2}$. Photolysis initially generates a pair of $\mathrm{CpMo}(\mathrm{CO})_{3}$ radicals. A $\mathrm{P}(\mathrm{OMe})_{3}$ molecule then coordinates to one member of the radical pair, yielding the 19e adduct $\mathrm{CpMo}(\mathrm{CO})_{3}\left(\mathrm{P}(\mathrm{OMe})_{3}\right)$, which can transfer an excess electron to the nearby $17 \mathrm{e} \mathrm{CpMo}(\mathrm{CO})_{3}$ radical to yield cationic and anionic disproportionation products.

Our group has investigated the generality of this photochemical disproportionation mechanism for six dimeric metal carbonyl complexes: $\mathrm{Mn}_{2}(\mathrm{CO})_{10}, \mathrm{Re}_{2}(\mathrm{CO})_{10}$, $\left[\mathrm{CpFe}(\mathrm{CO})_{2}\right]_{2}, \quad\left[\mathrm{CpRu}(\mathrm{CO})_{2}\right]_{2}, \quad\left[\mathrm{CpMo}(\mathrm{CO})_{3}\right]_{2}, \quad$ and $\left[\mathrm{CpW}(\mathrm{CO})_{3}\right]_{2}$ in the same $1: 4$ molar $\mathrm{P}(\mathrm{OMe})_{3}: \mathrm{CH}_{2} \mathrm{Cl}_{2}$ solvent mixture. ${ }^{48}$ The in-cage disproportionation mechanism was only observed for the molybdenum and tungsten dimers, but no disproportionation products were observed with the other four dimers studied. Formation of a 19e adduct occurred to a significant extent upon reaction of $\mathrm{P}(\mathrm{OMe})_{3}$ with the $17 \mathrm{e}$ iron and ruthenium radical products, but no electron transfer was observed; this is due to 
the fact that the 19e iron and ruthenium adducts localize their excess electron density at a ligand away from the metal center. ${ }^{49}$ For the manganese and rhenium species, no formation of a 19e adduct was observed.

Should the radicals (either the 17e or 19e species) diffuse out of the solvent cage prior to undergoing a disproportionation reaction, they may still undergo disproportionation on diffusion-limited time scales via a different mechanism ${ }^{44,50}$ or participate in other chemical reactions. The "in-cage" mechanism highlights another example of the importance of solvent-caging in the reactions of radical photoproducts arising from M-M bond cleavage.

\subsection{Influence of Bridging Ligands on M-M Bond Cleavage}

A large number of organometallic dimers contain bridging ligands to which both metal atoms are directly bonded. Considering that photochemical cleavage of such dimers may require breaking both an $\mathrm{M}-\mathrm{M}$ bond as well as one or more metal-ligand bonds, it is not immediately clear how the presence of bridging ligands will influence the observed photochemistry. A reasonable expectation is that the bridging ligands may bind the two halves of the dimer together more strongly, preventing efficient photolysis to form 17e radicals.

Among the most widely studied, prototypical metal carbonyl dimers to contain bridging ligands is the $\left[\mathrm{CpFe}(\mathrm{CO})_{2}\right]_{2}$ dimer. $\left[\mathrm{CpFe}(\mathrm{CO})_{2}\right]$ exists in solution primarily as a mixture of cis and trans isomers, each with 2 terminal and 2 bridging CO ligands, with nonbrdiged isomers also present. ${ }^{5-54}$ Visible photolysis of this compound in solution readily yields the corresponding 17e radicals (see Figure 5, top panel), along with significant bleaching of the parent bridging band in the TRIR spectrum..$^{55,56}$ Thus it appears that cleavage of the M-M bond to form $17 \mathrm{e}$ radicals is not significantly hindered by the presence of the bridging $\mathrm{CO}$ ligands.

Indeed, similar results have been observed regarding the photochemistry of other CO-bridged complexes containing formal $\mathrm{M}-\mathrm{M}$ bonds. The ruthenium congener of the iron dimer, $\left[\mathrm{CpRu}(\mathrm{CO})_{2}\right]_{2}$, similarly exists as a mixture of cis and trans bridged isomers, along with two nonbridged isomers, in polar solutions. ${ }^{57,58}$ Solution-phase photolysis at $400 \mathrm{~nm}$ again leads to efficient formation of the corresponding 17e radicals, with significant depletion observed for the bridging $\mathrm{CO}$ band of the parent species, indicating photochemical dissociation of the bridged parent complex ${ }^{49}$ Likewise, the photochemistry of $\mathrm{CO}_{2}(\mathrm{CO})_{8}$, which is characterized by a dibridged structure of $C_{2 v}$ symmetry, ${ }^{59-61}$ has been studied on the microsecond time scale following $355 \mathrm{~nm}$ excitation, and this too leads to efficient formation of the corresponding $17 \mathrm{e} \mathrm{Co}(\mathrm{CO})_{4}$ radicals. $^{62}$ It appears that bridging $\mathrm{CO}$ ligands do not significantly hinder cleavage of the $\mathrm{M}-\mathrm{M}$ bond of a dimer to yield the corresponding radical halves.

However, if the bridging ligand is something other than a $\mathrm{CO}$, the story may be different, as other bridging ligands may hold the metal centers together more strongly. Matrix isolation studies have demonstrated that photolysis of $\left[\mathrm{RhCl}(\mathrm{CO})_{2}\right]_{2}$, a dimer bridged by its two $\mathrm{Cl}$ ligands, yields
CO-loss products but retains the bridged $\mathrm{Rh}_{2} \mathrm{Cl}_{2}$ bridging unit (Figure 5 ) ${ }^{63}$ Actually in this complex, structural analyses indicate that the $\mathrm{Rh}$ atoms are not even significantly bonded to one another, and thus, by implication, the Rh$\mathrm{Cl}$ bonds must be almost solely responsible for maintaining the dimeric structure upon photochemical excitation. ${ }^{64,65} \mathrm{In}$ this regard, it is worth noting that $\mathrm{M}-\mathrm{Cl}$ bonds are, on average, substantially stronger than $\mathrm{M}-\mathrm{CO}$ bonds, providing a likely explanation for the observations described thus far. A typical $\mathrm{M}-\mathrm{Cl}$ bond strength is in the range of $6 \mathrm{o}-8 \mathrm{o} \mathrm{kcal} / \mathrm{mol}{ }^{66,67}$ while $\mathrm{M}-\mathrm{CO}$ bonds are typically $30-45 \mathrm{kcal} / \mathrm{mol} .^{25-27}$ The CO-bridged dimers are also known to undergo fluxional rearrangements of the carbonyl ligands, though these rearrangements at thermal equilibrium are expected to be too slow to influence the present experiments on the picosecond time scale. However, when the dimers are electronically or vibrationally excited, it is not unreasonable to think that the barriers to fluxional rearrangements of the CO ligands could be temporarily lowered, thus allowing the bridging $\mathrm{M}-\mathrm{CO}$ bonds to be broken more readily. This suggestion is only speculative at this point, though, and further exploration on this topic may be warranted.

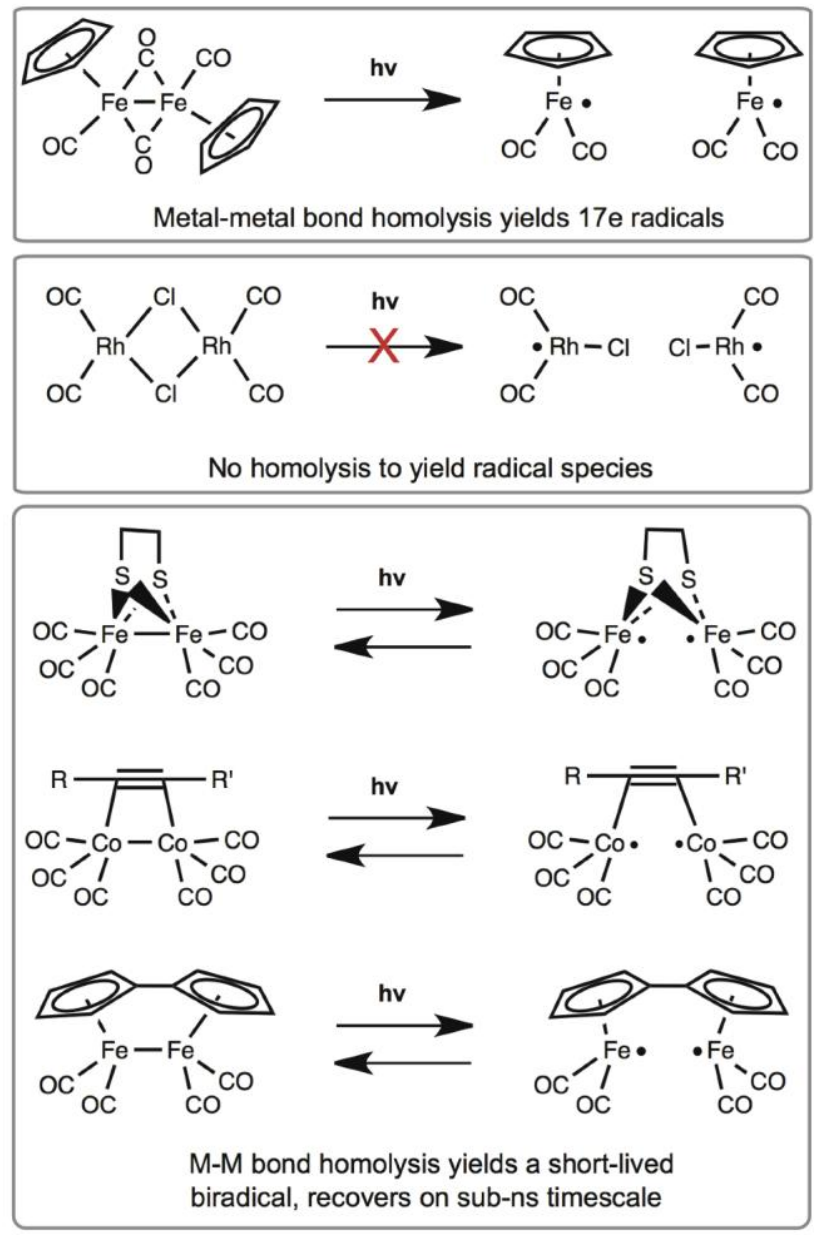

Figure 5. Representative photochemical dynamics observed for metal carbonyl dimers bridged by various ligands. Photochemical excitation of CO-bridged metal carbonyl dimers typically leads to facile formation of the corresponding $17 \mathrm{e}$ radicals, whereas excitation of similar metal carbonyl dimers 
bridged by other ligands may result in a lack of M-M bond cleavage, or transient $\mathrm{M}-\mathrm{M}$ bond cleavage followed by rapid reformation of the M-M bond.

Of course, a wide variety of other bridging ligands can be found in metal carbonyl dimers. For example, the photochemistry of a series of metal carbonyl dimers containing ( $\mu_{2}$-SRS) bridging ligands, where $\mathrm{R}$ is a short alkyl chain (Figure 5), have been investigated for their potential as biomimetic hydrogenase complexes. ${ }^{68,69}$ Photoexcitation of these complexes leads to transient $\mathrm{M}-\mathrm{M}$ bond cleavage followed by rapid recombination of the metal radicals to replenish the parent complex on the timescale of ca. 150 ps. Thus these bridges serve as a tether, holding the two halves of the dimer together, effectively preventing overall dissociation of the M-M bond. Similarly, ultrafast studies of alkyne bridged ( $\mu_{2}$-alkyne) $\mathrm{Co}_{2}(\mathrm{CO})_{6}$ complexes observed formation of transient diradical M-M bond cleavage intermediates (Figure 5), which reformed the parent complex on the ultrafast timescale (in 38-71 ps). ${ }^{70}$ Recent experiments by our group have sought to investigate the photoisomerization mechanism of a class of dimeric fulvalene metal carbonyl complexes, which have attracted significant interest for their potential solar energy storage applications. ${ }^{71,72}$ The complexes studied, $\mathrm{FvFe}_{2}(\mathrm{CO})_{4}$ and $\mathrm{FvRu}_{2}(\mathrm{CO})_{4}$, are analogous to the cyclopentadienyl-based metal carbonyls, $\left[\mathrm{CpFe}(\mathrm{CO})_{2}\right]_{2}$ and $\left[\mathrm{CpRu}(\mathrm{CO})_{2}\right]_{2}$ discussed earlier in this section (see bottom of Figure 5). Interestingly, no long lived 17e radicals are formed upon photochemical excitation of the fulvalene complexes, and this can be attributed to the carboncarbon linkage that bridges the two halves of the fulvalene ligand, which is absent in the cyclopentadienyl analogues. Instead of the formation of 17e radicals, transient $\mathrm{M}-\mathrm{M}$ bond cleavage occurs, followed predominantly by rapid, picosecond time scale recovery of the corresponding parent complexes.

Thus we see that the influence of bridging ligands on the dissociation of $\mathrm{M}-\mathrm{M}$ bonded dimers can be varied, and in many cases bridging ligands can significantly modulate the photochemistry of M-M bonded complexes by effectively preventing overall M-M bond cleavage. Similar effects will come into play as we look at the photochemistry of larger metal carbonyl complexes, as bonds to multiple distinct metal centers in a cluster can also serve as a tether between transiently cleaved M-M bonds.

\section{Photochemistry of Trimetallic Metal Carbonyl Clusters}

We will next take a look at the primary photochemistry of trimetallic metal carbonyl clusters by reviewing ultrafast spectroscopic studies on the three group 8 homoleptic metal carbonyl trimers, with an emphasis on the photochemical pathways involving changes in $\mathrm{M}-\mathrm{M}$ bonding.

\section{1. $\mathrm{Fe}_{3}(\mathrm{CO})_{12}$}

Triiron dodecacarbonyl $\left(\mathrm{Fe}_{3}(\mathrm{CO})_{12}\right)$ exists in the solution phase primarily as an isomer containing all terminal CO ligands, with a minor fraction of a second isomer containing two bridging $\mathrm{CO}$ ligands also present (see Figure 6). ${ }^{73-75}$ The fraction of the bridged isomer has been estimated at $5-10 \%$ of the total population of $\mathrm{Fe}_{3}(\mathrm{CO})_{12}$ mole- cules, though the ratio of isomers varies with the choice of solvent. ${ }^{76}$

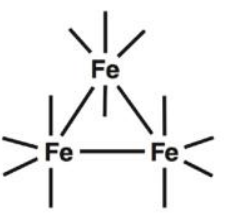

(major isomer)

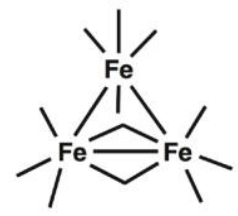

(minor isomer)
Figure 6. Structures of the $\mathrm{Fe}_{3}(\mathrm{CO})_{12}$ isomers present in the solution phase. The all-terminal structure (left) is the species predominantly present in solution, with the bridged structure as a minor isomer.

We have used picosecond TRIR spectroscopy to examine the primary photochemistry of $\mathrm{Fe}_{3}(\mathrm{CO})_{12}$ in both nonpolar (cyclohexane) and polar (methanol) solvents following 267 and $400 \mathrm{~nm}$ excitation. ${ }^{77}$ At both excitation wavelengths and in both solvents, the primary transient species observed following photoexcitation involve M-M bond cleavage intermediates and/or vibrationally excited parent molecules that relax on the ultrafast time scale. Ca. $94 \%$ of the parent bleach intensity recovers within $1 \mathrm{~ns}$ following $400 \mathrm{~nm}$ excitation in cyclohexane, while ca. $88 \%$ recovers on the same time scale when $267 \mathrm{~nm}$ excitation is used; thus more long-lived photoproducts are generated at shorter excitation wavelengths. The TRIR spectra collected following $400 \mathrm{~nm}$ excitation in cyclohexane are shown in Figure 7, along with representative structures for the transient photoproducts observed. The majority of the transient photoproduct signals are consistent with a modified $\mathrm{Fe}_{3}(\mathrm{CO})_{12}$ structure containing all terminal carbonyls in which one or more Fe-Fe bond is elongated relative to the ground state structure. DFT frequency calculations yield similar predicted infrared spectra for structures with one, two, or all three Fe-Fe bonds elongated, and thus it is difficult to say with any reasonable level of certainty how many Fe-Fe bonds are transiently cleaved (indeed, a mixture may be present). The same will be true for the transient intermediate observed for the osmium congener (vide infra). A weak transient bridging carbonyl band is also visible, though its low intensity (comparable to that of the bleach for the bridging band of the bridged parent isomer) suggests that it corresponds to a photoproduct arising from excitation of the bridged isomer, and this species was assigned to the structure shown at the top right of Figure 7. DFT calculations were helpful in reaching these structural assignments. 


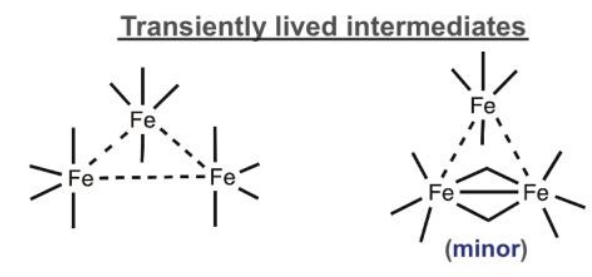

Longer-lived fragmentation/CO-loss products
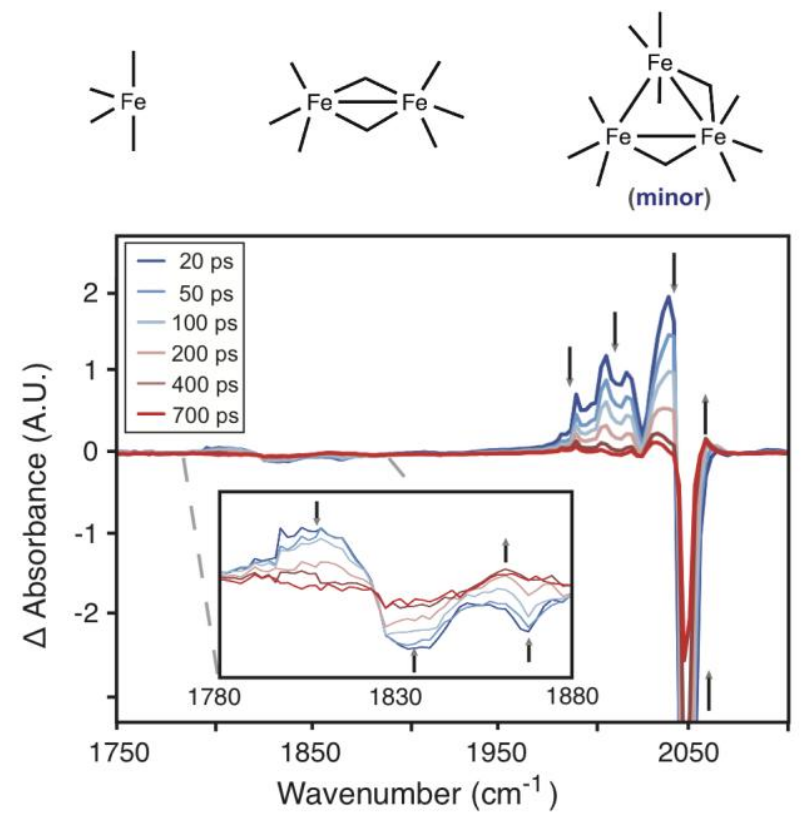

Figure 7. TRIR spectra of $\mathrm{Fe}_{3}(\mathrm{CO})_{12}$ following $400 \mathrm{~nm}$ excitation in cyclohexane solution (bottom) along with the identities of the transiently-lived and long-lived photoproducts observed (top). Reprinted (adapted) with permission from (J.P. Lomont, A.J. Shearer, S.C. Nguyen, C.B. Harris, Organometallics 32 (2013) 2178.). Copyright (2013) American Chemical Society.

At longer delay times (> ca. $200 \mathrm{ps}$ ), the presence of the long-lived products $\mathrm{Fe}(\mathrm{CO})_{4}$ and $\mathrm{Fe}_{2}(\mathrm{CO})_{8}$ could also be identified, and these species must arise from overall fragmentation of the $\mathrm{Fe}_{3}$ skeleton. Additional bands are assigned to a minor amount of the CO-loss product, $\mathrm{Fe}_{3}(\mathrm{CO})_{11}{ }^{78,79}$ As mentioned earlier, the relative fraction of the long-lived photoproducts formed appears to increase at the lower excitation wavelength of $267 \mathrm{~nm}$, which is not a surprising observation since a higher excitation energy is expected to facilitate fragmentation of the cluster. The observations regarding the photochemistry of this complex in cyclohexane and methanol solvents were generally similar, with the same transient and long-lived products being formed in both solvent environments. The similarity of the spectra in the more coordinating solvent, methanol, to those collected in cyclohexane suggests that methanol does not coordinate significantly to the transient $\mathrm{M}-\mathrm{M}$ bond cleavage intermediates. This could be due to vibrational excitation inhibiting solvation, or to the $\mathrm{M}-\mathrm{M}$ bond not being extended to a large enough distance to allow insertion of a methanol molecule. It is also possible that if a methanol molecule does transiently insert into the cleaved metal-metal bond, the potential energy surface for reforming the M-M bond may be purely downhill, such that a temporarily inserted methanol molecule is expelled to reform the M-M bond.

An earlier study by our group characterized the photochemistry of $\mathrm{Fe}_{3}(\mathrm{CO})_{12}$ in cyclohexane solution using picosecond UV-Vis spectroscopy. ${ }^{80}$ In that study it was concluded that the transient species observed with a lifetime of ca. 150 ps contained bridging carbonyls, and the time constant for decay of these transients and recovery of the parent complex was interpreted in terms of the energetic barrier for isomerization from a bridged to all-terminal complex. The TRIR results discussed here clarify that the majority of the transient intermediates do not, in fact, contain bridging $\mathrm{CO}$ groups, suggesting that the interpretation of the time constant for decay of the transients was incorrect. In the picosecond UV-Vis study, the long-lived photoproducts were concluded to be mono- and dinuclear fragmentation products, which is consistent with the observations made in the TRIR study. Overall the TRIR technique is more structurally specific and provides a clearer picture of the photochemical reactivity, relative to the transient UV-Vis results.

\section{2. $\mathrm{Ru}_{3}(\mathrm{CO})_{12}$}

Turning next to the ruthenium congener, triruthenium dodecacarbonyl $\left(\mathrm{Ru}_{3}(\mathrm{CO})_{12}\right)$ is characterized by an allterminal $\mathrm{CO}$ structure, with a triangular skeleton of three $\mathrm{Ru}$ atoms each bearing four terminal CO ligands (similar to the major isomer of $\left.\mathrm{Fe}_{3}(\mathrm{CO})_{12}\right)$. $^{81,82}$ Only this one isomer is present in solutions of $\mathrm{Ru}_{3}(\mathrm{CO})_{{ }_{2}}$.

Picosecond TRIR spectroscopy was used to study the photochemistry of this complex following 267 and 400 $\mathrm{nm}$ excitation in cyclohexane and THF solutions. ${ }^{83} \mathrm{~A}$ transient $\mathrm{M}-\mathrm{M}$ bond cleavage product is observed to contain a bridging $\mathrm{CO}$ group, and this species exhibits a lifetime of $60 \pm 5 \mathrm{ps}$ following $400 \mathrm{~nm}$ excitation in cyclohexane solution. A second species containing a bridging $\mathrm{CO}$ is observed with a lifetime that extends beyond the picosecond timescale, and this corresponds to a CO-loss species. Figure 8 summarizes the primary photochemistry observed. DFT calculations were used to facilitate assignments of the molecular structures of these species. Both of these products exhibit similar dynamics following 267 and 400 nm excitation.

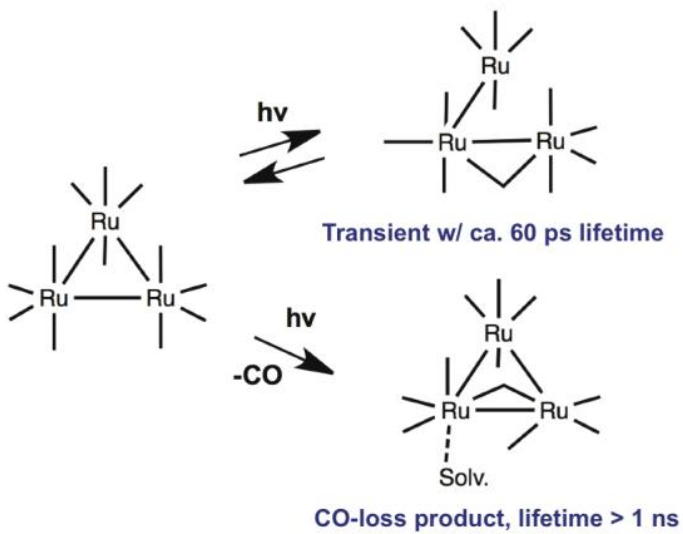


Figure 8. Summary of the photochemical dynamics observed for $\mathrm{Ru}_{3}(\mathrm{CO})_{12}$ based on picosecond TRIR experiments following visible or ultraviolet excitation.

Similar photochemistry was observed when either cyclohexane or THF was used as the solvent. It was not initially clear whether THF would block formation of bridged species by solvating the metal centers. Additionally, previous reports had indicated that THF blocks photofragmentation (which had been observed on longer time scales in other solvents), but the mechanism behind this behavior was unclear. ${ }^{84-86}$ In the TRIR experiments, the use of THF as the solvent did not inhibit formation of bridging carbonyl complexes. No significant differences in the primary photochemistry were observed between the experiments conducted in cyclohexane and THF solvents, nor was photofragmentation observed in either solvent. Thus it would appear that fragmentation of the metal cluster may be a secondary step in the reactivity of the long-lived CO-loss intermediate observed to form on the picosecond timescale. The role of THF in blocking this fragmentation remains speculative and no definitive insight was offered by the results of the TRIR experiments.

More recent studies using time-resolved X-ray experiments appear to have uncovered an additional long-lived photoproduct in the photochemistry of $\mathrm{Ru}_{3}(\mathrm{CO})_{12}$, which is the di-carbonyl loss species $\mathrm{Ru}_{3}(\mathrm{CO})_{10}{ }^{87,88}$ This represents a rare example of di-carbonyl loss occurring following a single photon absorption event in the solution phase. ${ }^{8-92}$ This species apparently escaped detection in the TRIR experiments, as it is believed to contain only terminal $\mathrm{CO}$ ligands and thus may not have been readily identifiable in the presence of other terminal $\mathrm{CO}$ stretching bands.

\section{3. $\mathrm{Os}_{3}(\mathrm{CO})_{12}$}

Finally we look at the photochemistry of osmium dodecacarbonyl $\left(\mathrm{Os}_{3}(\mathrm{CO})_{12}\right)$, which adopts a ground state structure of $\mathrm{D}_{3 \mathrm{~h}}$ symmetry containing no bridging $\mathrm{CO}$ groups, similar to that of $\mathrm{Ru}_{3}(\mathrm{CO})_{12}{ }^{93,94} \mathrm{TRIR}$ experiments were used to study the primary photochemistry of this complex in cyclohexane solution following 267 and 400 $\mathrm{nm}$ excitation, and the spectra collected following $400 \mathrm{~nm}$ excitation are shown in Figure 9. ${ }^{77}$

The primary photochemical process observed following 267 or $400 \mathrm{~nm}$ excitation is metal-metal bond cleavage to yield a transiently lived intermediate also containing all terminal CO-ligands. Similar to the case for the iron congener, it is not clear whether one or more Os-Os bonds are transiently cleaved. In cyclohexane solution roughly $95 \%$ of the initially excited molecules relax to reforms the parent on a time scale of ca. 150 ps following $400 \mathrm{~nm}$ excitation, while ca. $89 \%$ of the parent signal intensity recovers on a similar time scale following $267 \mathrm{~nm}$ excitation. ${ }^{77}$ The primary long-lived photoproduct observed is a CO-loss species, $\mathrm{Os}_{3}(\mathrm{CO})_{11}$, whose structural assignment is made based on comparison to previous literature reports. ${ }^{95}$
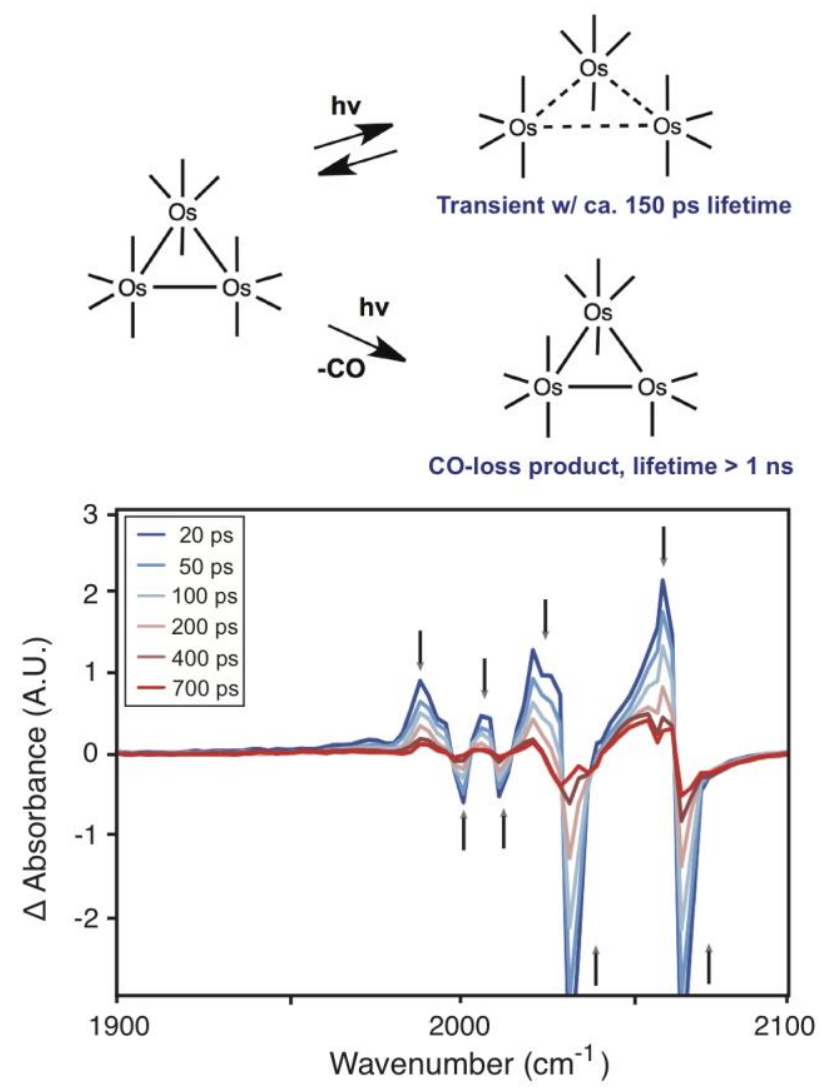

Figure 9. TRIR spectra of $\mathrm{Os}_{3}(\mathrm{CO})_{12}$ following $400 \mathrm{~nm}$ excitation in cyclohexane solution (bottom) along with the structures of the parent complex and the photoproducts observed (top). Reprinted (adapted) with permission from (J.P. Lomont, A.J. Shearer, S.C. Nguyen, C.B. Harris, Organometallics 32 (2013) 2178.). Copyright (2013) American Chemical Society.

The $\mathrm{Os}_{3}(\mathrm{CO})_{12}$ cluster doesn't appear to fragment to any detectable extent upon photoexcitation at either wavelength tested, suggesting that the $\mathrm{Os}_{3}$ backbone structure is more robust with regard to photoexcitation/photodegradation. No bridging $\mathrm{CO}$-stretching bands were observed for either the transiently-lived or long-lived photoproducts observed in our study of this cluster. The subsequent photochemistry of the $\mathrm{Os}_{3}(\mathrm{CO})_{12}$ cluster on diffusion-limited time scales is expected to proceed through reactivity of the $\mathrm{CO}$-loss product $\left(\mathrm{Os}_{3}(\mathrm{CO})_{11}\right)$, as this was the only long-lived product observed.

\subsection{Comparison of Reactivity}

As we seek to compare the reactivity of the group 8 metal carbonyl trimers, some common themes stand out. The first is that excitation at UV or visible wavelengths consistently leads to transient cleavage of $\mathrm{M}-\mathrm{M}$ bonds in the triangular $\mathrm{M}_{3}$ skeleton. Another photochemical pathway observed to some extent in each congener is dissociation of a $\mathrm{CO}$ ligand, which is not surprising considering the body of studies demonstrating photochemical CO loss from metal carbonyl complexes. For a given cluster, UV $(267 \mathrm{~nm})$ and visible (40o $\mathrm{nm})$ photolysis yielded the same products in each case, with lower wavelength photolysis leading to a greater fraction of long-lived (i.e. 
fragmentation or CO-loss) products formed, relative to transiently lived $\mathrm{M}-\mathrm{M}$ bond cleavage isomers.

However, it turns out that much of the behavior of the three group 8 metal carbonyl trimers is quite nuanced. $\mathrm{Fe}_{3}(\mathrm{CO})_{12}$, for example, is the only cluster for which products arising from fragmentation of the $\mathrm{M}_{3}$ skeleton were observed. As was discussed in an earlier publication, photochemical fragmentation of the iron cluster likely proceeds more readily due to the weaker Fe-Fe bonds holding together the $\mathrm{Fe}_{3}$ skeleton, relative to those of the ruthenium and osmium congeners. ${ }^{77,96-98}$ It remains possible that higher energy excitation could lead to fragmentation of the $\mathrm{M}_{3}$ skeletons in the ruthenium and osmium clusters as well. The solvent may likely play a significant role in dissipating excess excitation energy such that fragmentation of the $M_{3}$ skeletons in the ruthenium and osmium clusters is not observed.

Whereas CO dissociation formed the only long-lived products for the ruthenium and osmium clusters, CO loss was only a minor pathway observed in the photochemistry of the iron cluster. This carries implications for the subsequent photochemical reactivity occurring on longer time scales: photochemical reactions involving $\mathrm{Fe}_{3}(\mathrm{CO})_{12}$ will likely proceed primarily through mono- and dinuclear intermediates, while reactions of $\mathrm{Ru}_{3}(\mathrm{CO})_{12}$ and $\mathrm{Os}_{3}(\mathrm{CO})_{12}$ will proceed through trinuclear $\mathrm{CO}$ loss species. The trinuclear CO-loss products may, of course, also undergo subsequent fragmentation to yield mono- and/or di-nuclear intermediates themselves.

In terms of the structures of the transient intermediates observed, both the iron and ruthenium clusters formed short-lived $\mathrm{M}-\mathrm{M}$ bond cleavage transients containing bridging $\mathrm{CO}$ groups, while the osmium cluster did not. However, for the iron cluster, only the bridged parent isomer led to the formation of transient intermediates exhibiting a bridging $\mathrm{CO}$ absorption, suggesting that perhaps no new bridging $\mathrm{CO}$ groups were actually formed, but instead that transient cleavage of a $\mathrm{M}-\mathrm{M}$ bond led to a shift in the frequency of the bridging $\mathrm{CO}$ groups already present in the parent isomer. Excitation of the allterminal $\mathrm{CO}$ ligand isomer of $\mathrm{Fe}_{3}(\mathrm{CO})_{12}$ did not lead to the formation of an intermediate containing bridging $\mathrm{CO}$ ligands. Only for the ruthenium cluster, then, were new bridging $\mathrm{CO}$ groups clearly formed in order to stabilize a photochemically cleaved M-M bond. It is also worth noting that all of the transiently-lived $\mathrm{M}-\mathrm{M}$ bond cleavage intermediates exhibited sub-nanosecond lifetimes, implying that they will not be involved in reactions occurring on diffusion-limited time scales in dilute solutions. Changes of solvent did affect the observed lifetimes to an extent, but no significantly longer-lived intermediates were generated by the use of more coordinating solvents.

Having summarized the photochemistry of several metal-metal bonded complexes based on a single transition metal element, we also consider what we predict might happen for the photochemistry of some mixedmetal complexes. For example, the linear complex $(\mathrm{OC})_{5} \operatorname{ReOs}(\mathrm{CO})_{4} \operatorname{Re}(\mathrm{CO})_{5}$, or the mixed-metal triangular cluster $\mathrm{Ru}_{2} \mathrm{Fe}(\mathrm{CO})_{12}$. For the former linear complex, UV photoexcitation seems likely to cleave one (or perhaps even both) of the metal-metal bonds; this is based on comparisons to transition metal dimers such as $\mathrm{Mn}_{2}(\mathrm{CO})_{10}, \mathrm{Re}_{2}(\mathrm{CO})_{10}$, along with the other dimeric complexes discussed in section 2, which similarly contain metal carbonyls held together by a single metal-metal bond. For the later mixed metal cluster, the chemistry may be more difficult to predict, given the nuanced behavior of trimetallic clusters described in this section. For this reason, the photochemistry of heterotrimetallic clusters is a subject we feel warrants further investigation.

One final point of interest are the more recent timeresolved X-ray studies on the $\mathrm{Ru}_{3}(\mathrm{CO})_{12}$ cluster, which indicate a di-CO-loss process upon single-photon excitation. It has been suggested that the $\mathrm{Ru}_{3}(\mathrm{CO})_{10}$ photoproduct was not clearly resolved in the TRIR studies due to overlap of spectral bands in the terminal $\mathrm{CO}$-stretching region. The loss of two CO ligands via a single photon process in the solution phase is rare, but may be attributable to the lower $\mathrm{M}-\mathrm{CO}$ bond strengths associated with second row transition metals (relative to those in complexes of first and third row metals). ${ }^{99,100}$ If the suggestion that spectral overlap of the terminal-CO bands prevents definitive assignment of mono- vs. di-CO-loss processes in the TRIR spectra of these complexes, it may be worth undertaking further time-resolved X-ray experiments to examine the possibility of di-CO-loss processes in the iron and osmium clusters as well, though the expectation is certainly that the photon energies used in these studies is too low to cause di-CO-loss to occur via a single-photon event in the solution phase.

\section{Photochemistry of Tetrametallic and Larger Clusters}

Finally we will take a look at the limited number of existing mechanistic studies into the photochemistry of larger metal carbonyl clusters with the goal of gaining at least a basic understanding of the solution-phase photochemical behavior of the larger clusters. Few ultrafast studies have been performed on the larger clusters to date, so the information available on the primary photochemical processes is somewhat limited, although much of what is missing can likely be inferred to a reasonable extent based on comparisons to the results for the trinuclear clusters discussed in the previous section.

\section{1. $\mathrm{Co}_{4}(\mathrm{CO})_{12}$}

The tetracobalt dodecacarbonyl cluster $\left(\mathrm{Co}_{4}(\mathrm{CO})_{12}\right)$ adopts a $\mathrm{C}_{3 \mathrm{v}}$ structure with three bridging and nine terminal CO ligands. Three basal Co atoms are bridged by the three bridging $\mathrm{CO}$ ligands, with each basal Co also coordinated to two terminal CO ligands, and the final apical $\mathrm{Co}$ atom coordinated to three terminal $\mathrm{CO}$ ligands (see top structure in Figure 10). Each of the four Co atoms is connected by a single M-M bond. ${ }^{101}$ 


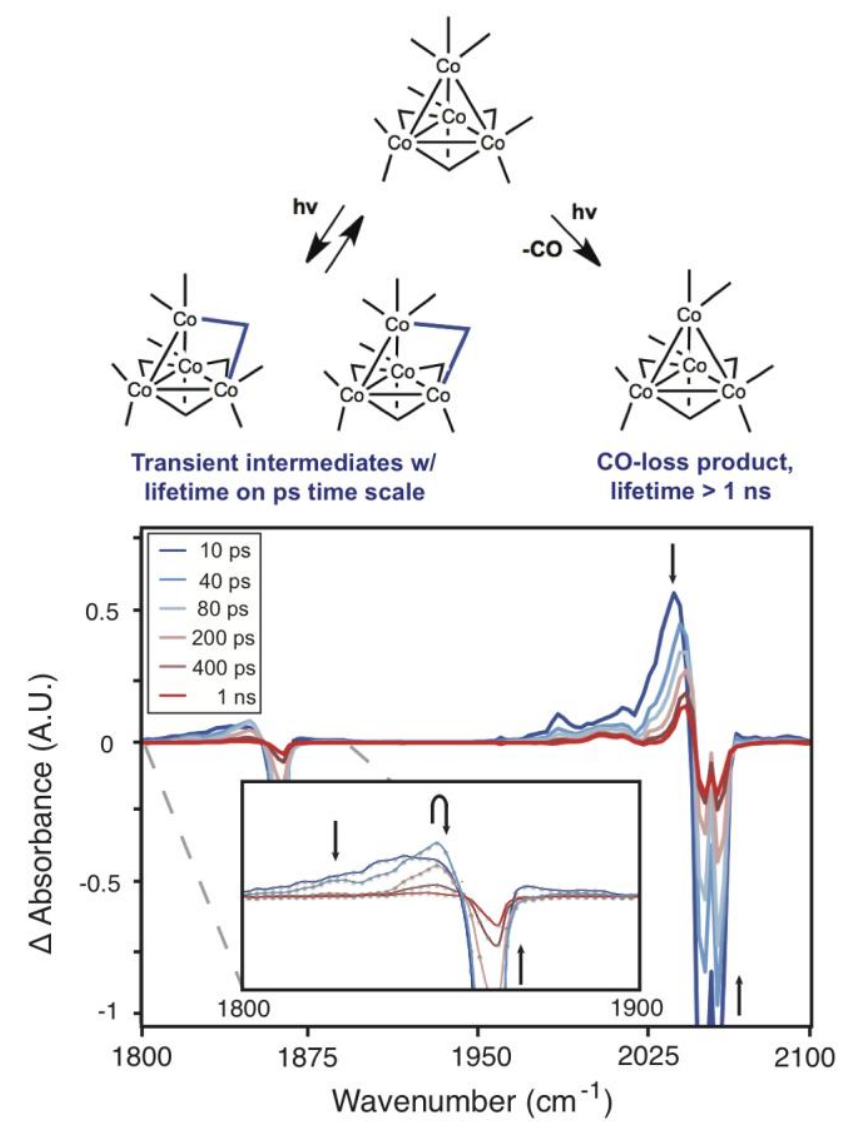

Figure 10. TRIR spectra of $\mathrm{Co}_{4}(\mathrm{CO})_{12}$ following $400 \mathrm{~nm}$ excitation in cyclohexane solution (bottom) along with the structures of the parent complex and the photoproducts observed (top). Reprinted (adapted) with permission from (J.P. Lomont, S.C. Nguyen, C.B. Harris, Organometallics 31 (2012) 4031.). Copyright (2012) American Chemical Society.

Picosecond TRIR experiments performed using 267 and $400 \mathrm{~nm}$ photolysis in cyclohexane and $\mathrm{CH}_{2} \mathrm{Cl}_{2}$ solutions uncovered the presence of two distinct transiently lived rearrangement isomers, both containing bridging carbonyls. ${ }^{102}$ The two transiently lived rearrangement isomers arise from cleavage of an apical-basal Co-Co bond, which is then bridged by a rearrangement of either a basal or apical terminal CO ligand to a bridging coordination mode (thus accounting for the two different rearrangement isomers observed). DFT calculations were used to correlate the lifetimes of the two rearrangement isomers to the enthalpic barriers for reversion to the parent complex (via transition state optimizations) and found good agreement between the calculated transition state barriers and the experimentally observed lifetimes. The lifetimes of the rearrangement isomers exhibit a solvent dependence, but their short (sub-nanosecond time scale) lifetimes indicate that no solvent molecules coordinate significantly to the unsaturated metal centers upon $\mathrm{Co}-\mathrm{Co}$ bond cleavage.

The only long-lived photoproduct observed upon photolysis of $\mathrm{Co}_{4}(\mathrm{CO})_{12}$ was a CO-loss product, indicating that the $\mathrm{Co}_{4}$ skeleton remained intact after relaxation of the initially excited species. No fragmentation products, such as $\mathrm{Co}(\mathrm{CO})_{3}, \mathrm{Co}(\mathrm{CO})_{4}, \mathrm{Co}_{2}(\mathrm{CO})_{8}$, or $\mathrm{Co}_{2}(\mathrm{CO})_{9}$, were detected. The photochemistry of $\mathrm{Co}_{4}(\mathrm{CO})_{12}$ on diffusionlimited timescales thus appears to be dictated by the reactivity of the CO-loss product, $\mathrm{Co}_{4}(\mathrm{CO})_{11}$, as no other longlived photoproducts were observed.

As a aside, Cotton had once, long ago, proposed a structure of $\mathrm{D}_{2 \mathrm{~d}}$ symmetry for the $\mathrm{Co}_{4}(\mathrm{CO})_{12}$ parent complex. DFT calculations were used to assess the stability of such a structure, but no corresponding minimum could be located. ${ }^{103}$

\section{2. $\mathbf{R h}_{4}(\mathrm{CO})_{12}$}

The tetranuclear cluster $\mathrm{Rh}_{4}(\mathrm{CO})_{12}$ predominantly adopts a $C_{3 v}$ structure in the solution phase, with nine terminal and three bridging $\mathrm{CO}$ ligands, very similar to that of the parent isomer of $\mathrm{Co}_{4}(\mathrm{CO})_{12}{ }^{104,105}$ The photochemistry of $\mathrm{Rh}_{4}(\mathrm{CO})_{12}$ has previously been reported in TRIR studies carried out on the nanosecond to microsecond time scales following $267 \mathrm{~nm}$ excitation. ${ }^{106}$ The only photoproduct observed was a CO-loss species, $\mathrm{Rh}_{4}(\mathrm{CO})_{11}($ solv.), which underwent isomerization and subsequently recombination with $\mathrm{CO}$ to reform the parent complex on diffusion-limited time scales.

To our knowledge, no ultrafast studies to date have examined the photochemistry of this tetrametallic cluster. Based on comparisons to all of the ultrafast work described earlier in this manuscript, one would expect the lifetimes of any transiently formed $\mathrm{M}-\mathrm{M}$ bond cleavage intermediates to be on the sub-nanosecond time scale. Thus, while such M-M bond cleavage transients are very likely formed, one could not expect to observe them on the time scale addressed in the only TRIR experiments carried out to date on this complex.

\section{3. $\mathbf{R h}_{6}(\mathbf{C O})_{16}$}

The solution-phase structure of $\mathrm{Rh}_{6}(\mathrm{CO})_{16}$ is characterized by an octahedral arrangement of the $\mathrm{Rh}_{6}$ skeleton, with 12 terminal and four bridging $\mathrm{CO}$ groups. ${ }^{107}$ The photochemistry of $\mathrm{Rh}_{6}(\mathrm{CO})_{16}$ has been studied via infrared spectroscopy following near-UV $\left(\lambda_{\text {irr }}>300 \mathrm{~nm}\right) \mathrm{CW}$ irradiation. The only observed photoproduct was a solventcoordinated CO-loss species, $\mathrm{Rh}_{6}(\mathrm{CO})_{15}($ solv.), with no photoproducts arising from fragmentation of the $\mathrm{Rh}_{6}$ backbone, nor further CO-loss species, having been reported. ${ }^{108}$ Thus the photochemistry of the $\mathrm{Rh}_{6}(\mathrm{CO})_{16}$ cluster on diffusion-limited time scales is believed to involve reactions of the $\mathrm{Rh}_{6}(\mathrm{CO})_{15}$ (solv.) photoproducts.

Based on comparisons to the other work described in this manuscript, it is believed that the initial excitation of the $\mathrm{Rh}_{6}(\mathrm{CO})_{16}$ parent molecule will also lead to transiently lived (sub-nanosecond lifetime) M-M bond cleavage intermediates that recover to rapidly reform the parent complex. The existing experimental work to date is quite limited, though, and since no ultrafast work on this species has been carried out, such M-M bond cleavage intermediates for the $\mathrm{Rh}_{6}(\mathrm{CO})_{16}$ cluster have never been directly observed.

The photochemistry of larger and larger clusters becomes increasingly difficult to study due to the multiple competing pathways possible, overlap of spectral reson- 
ances, and other factors. For this reason, there exist few studies on the larger metal carbonyl clusters, though the results of the studies described thus far demonstrate that substantial insight can likely be gained from timeresolved studies on these species.

\subsection{Comparison of Reactivity}

For each of the metal carbonyl clusters with four or more metal centers studied to date, solution-phase UV or visible photoexcitation leads to $\mathrm{CO}$-loss products as the only long-lived photoproducts, leaving the metal skeleton intact. The overall number of metal-metal and/or metalligand bonds that would need to be broken to cause fragmentation of the larger clusters presumably influences this. In addition to the role of the solvent in rapidly dissipating excess excitation energy, it seems that the multiple metal-metal bonds, and in some cases metalligand bonds, serve to tether the metal skeleton together such that transiently cleaved M-M bonds are reformed rapidly after photoexcitation.

To date, the only cluster with four or more metal centers whose photochemistry has been studied on the ultrafast time scale is $\mathrm{Co}_{4}(\mathrm{CO})_{12}$. For this cluster, similar to the metal carbonyl trimers in section 3, the majority of transient photoproducts containing cleaved M-M bonds recover on the sub-nanosecond time scale to reform the parent complex. We believe similar behavior very likely characterizes the primary photochemical events of other large metal carbonyl clusters, though the experimental data to verify this assertion has not, to date, been reported.

In terms of predictive value, the observations to date would seem to strongly suggest that most higher nuclearity metal clusters will not tend to undergo photofragmentation (via a single photon process, at least) in the solution phase. To our knowledge, the photochemistry of the other group 9 congeners of the clusters discussed in this section $\left(\mathrm{Ir}_{4}(\mathrm{CO})_{12}, \mathrm{Co}_{6}(\mathrm{CO})_{16}\right.$, and $\left.\mathrm{Ir}_{6}(\mathrm{CO})_{16}\right)$ has not been studied. However, the available data lead us to predict that their photochemistry will be dictated by CO-loss products, and their initial photochemical excitation will almost certainly involve the formation of transiently lived $\mathrm{M}-\mathrm{M}$ bond cleavage transients with sub-nanosecond lifetimes.

\subsection{The Nature of Transient M-M Bond Cleavage In-} termediates

Having now examined the results of a number of ultrafast spectroscopic studies on the primary photochemistry of transition metal dimers and clusters, we will examine in slightly more detail the nature of, and the spectroscopic evidence for, the species that form upon photochemical homolysis of a M-M bond. A driving question for exploring these intermediates in more detail is the following: how do we know a M-M bond was cleaved?

In some cases the evidence is entirely straightforward; in the case of many transition metal dimers, which are among the simplest compounds to contain M-M bonds, we have clear evidence for the cleavage of $\mathrm{M}-\mathrm{M}$ bonds to form the corresponding radical products. For dimers such as $\mathrm{Mn}_{2}(\mathrm{CO})_{10}$ or $\left[\mathrm{CpFe}(\mathrm{CO})_{2}\right]_{2}$, TRIR experiments clearly detect the products of $\mathrm{M}-\mathrm{M}$ bond homolysis, which are the corresponding 17e radical halves of each dimer (e.g. $\mathrm{Mn}(\mathrm{CO})_{5}$ and $\left.\mathrm{CpFe}(\mathrm{CO})_{2}\right)$.

But let us consider a less straightforward example: in the case of $\mathrm{FvFe}_{2}(\mathrm{CO})_{4}$, the species assigned to a transient $\mathrm{M}-\mathrm{M}$ bond cleavage product is short lived and reforms the parent complex on the ultrafast time scale (refer back to Figure 5). In this case, a vibrationally excited parent complex (even one with the M-M bond essentially intact) would be expected to display similar signals in the TRIR spectrum to a species with the M-M bond cleaved; vibrational overtone bands are typically red-shifted relative to those of the parent complex, and this is similar in principle to the spectrum observed experimentally (see Ref. 72). Too, the overall lifetime of the proposed M-M bond cleavage product is at least plausibly commensurate with the expected time scale for vibrational relaxation in a metal carbonyl complex. So, what evidence is there that the M-M bond is actually cleaved? After all, the spectral signatures for $\mathrm{M}-\mathrm{M}$ bond cleavage and those for a vibrationally excited parent molecule with the M-M bond intact are expected to be quite similar.

In this case, the fact that the Fe-Fe bond of $\left[\mathrm{CpFe}(\mathrm{CO})_{2}\right]_{2}$ is cleaved provides some of the strongest evidence that the Fe-Fe bond in $\mathrm{FvFe}_{2}(\mathrm{CO})_{4}$ is also cleaved. The similarity of their structures and UV-Vis spectra $^{72,109}$ are strong indication that their photochemical behavior will be similar. There is more evidence too: the ruthenium congener, $\mathrm{FvRu}_{2}(\mathrm{CO})_{4}$, possesses a nearly identical structure to its iron analogue, and the ruthenium complex undergoes quantitative photoisomerization to a stable photoisomer containing no M-M bonds. This photoisomerization mechanism has been studied in detail, and the first step involves photochemical cleavage of the Ru-Ru bond, a step which is entirely essential for the subsequent photoisomerization..$^{71}$ Again, the similar structure and UV-Vis spectra ${ }^{71,72}$ for these two complexes suggest their primary photochemistry will be quite similar. Thus while no long-lived products can be detected to prove that the M-M bond of $\mathrm{FvFe}_{2}(\mathrm{CO})_{4}$ has been cleaved, there is a body of surrounding evidence supporting the notion that the Fe-Fe bond is genuinely cleaved.

It remains entirely possible, and even likely, that the vibrationally excited bands of parent molecules with $\mathrm{M}-\mathrm{M}$ bonds intact overlap those of the transient $\mathrm{M}-\mathrm{M}$ bond cleavage species, and as such it remains difficult to assess the relative yields of each process and the individual time scales for decay of each to the ground state parent species. There very likely exist other cases where less-direct evidence exists to support or refute the transient photochemical cleavage of a M-M bond. Indeed, picosecond TRIR spectroscopy may not always be able to distinguish between vibrationally excited parent molecules and those in which a M-M bond has been transiently cleaved. The fact that the lifetimes and vibrational spectra of vibrationally excited intermediates and $\mathrm{M}-\mathrm{M}$ bond cleavage transients are both typically expected to be (again, at least plausibly) similar make this a potentially hazy issue to 
sort out at times. We have carried out DFT calculations on several metal carbonyl complexes with one (or more) $\mathrm{M}-\mathrm{M}$ bond(s) elongated relative to the parent structure, and we have found that such elongation of $\mathrm{M}-\mathrm{M}$ bonds is very often predicted to yield red-shifts of the COstretching absorptions, similar to what one might also associate with a vibrationally excited complex.

Moving to larger clusters, with regard to the observation of M-M bond cleavage transients in $\mathrm{Fe}_{3}(\mathrm{CO})_{12}$, the strongest evidence that $\mathrm{M}-\mathrm{M}$ bonds are cleaved is that some fraction of the parent molecules actually do fragment to produce $\mathrm{Fe}(\mathrm{CO})_{4}$ and $\mathrm{Fe}_{2}(\mathrm{CO})_{8}$ as the principal long-lived photoproducts. The fact that increasing the excitation energy into the UV decreases the relative fraction of transient intermediates that recovers to regenerate parent molecules, relative to the amount of fragmentation products formed, supports the notion that excess excitation energy promotes further M-M bond cleavage to allow fragmentation of the cluster. Again, the spectral signatures for vibrationally excited parent complexes with $\mathrm{M}$ $\mathrm{M}$ bonds intact are expected to be similar to those for M$\mathrm{M}$ bond cleavage transients, making it difficult to ascertain the relative quantities of each species present at any given delay time.

In the case of $\mathrm{Ru}_{3}(\mathrm{CO})_{12}$, the fact that a transient bridging carbonyl absorption is observed provides clear proof that a M-M bond was cleaved; were this not the case, there would be no impetus for rearrangement of a terminal $\mathrm{CO}$ to a bridging conformation. Here the timescale for decay of the bridging $\mathrm{CO}$ absorption allows clear identification of the lifetime of the transient M-M bond cleavage product.

For $\mathrm{Os}_{3}(\mathrm{CO})_{12}$, there is less direct evidence to support the notion that a M-M bond is transiently cleaved; the cluster does not fragment, and no transient bridging carbonyl bands are observed. Further work is actually currently underway in our laboratory to compare the spectrum of vibrationally excited $\mathrm{Os}_{3}(\mathrm{CO})_{12}$ to that excited at $\mathrm{UV}$ and visible wavelengths in the solution phase. At this point in time, comparison to the numerous metal carbonyl dimers and other metal carbonyl trimers studied would suggest that at least some fraction of the parent complex undergoes transient cleavage of an Os-Os bond. That the photon energy in these experiments is greater than the bond enthalpy of a single M-M bond also suggests its quite reasonable to expect transient $\mathrm{M}-\mathrm{M}$ bond cleavage to at least some extent (this is true for all of the complexes discussed in this manuscript).

The only larger metal carbonyl cluster whose ultrafast photochemistry has been studied is $\mathrm{Co}_{4}(\mathrm{CO})_{12} \cdot{ }^{102}$ For this complex two distinct bridging photoproduct bands were observed with distinct lifetimes, allowing the clear identification of two different transient M-M cleavage intermediates containing bridging carbonyls. DFT calculations were used to identify the enthalpic barriers for reversion of each isomeric intermediate to the parent complex, and good agreement was found between the calculated energy barriers and the experimentally observed time constants.
These facts support the assignments of the intermediates observed experimentally as bridged rearrangement isomers with $\mathrm{M}-\mathrm{M}$ bonds genuinely cleaved; similar to the case for $\mathrm{Ru}_{3}(\mathrm{CO})_{12}$, were not a M-M bond cleaved, there would be no reason (in terms of electron counts at the metal centers) to expect a terminal $\mathrm{CO}$ ligand to rearrange to a bridging conformation.

In this section we hope we have made clear the evidence surrounding transient cleavage of $\mathrm{M}-\mathrm{M}$ bonds as well as the difficulty that can arise in separating the spectral signatures of $\mathrm{M}-\mathrm{M}$ bond cleavage transients from those of vibrationally excited parent complexes with all $\mathrm{M}-\mathrm{M}$ bonds intact. While we have discussed the evidence surrounding M-M bond cleavage in only a handful of species, we hope the pedagogy behind these discussions will serve as a tool to readers who wish to apply similar analyses to other complexes not covered here. In cases where isolated spectral signatures of the M-M cleavage transients exist (e.g. new bridging $\mathrm{CO}$ absorptions or other clearly identifiable signatures), the life time(s) and relative yield(s) of M-M bond cleavage transients can be easier to sort out. In other cases we must rely on less direct evidence, and comparison to knowledge of related complexes can often be quite informative.

\section{CONCLUSIONS}

The photochemistry of metal carbonyl dimers and clusters is a topic of significant interest due to the broad range of reactions catalyzed by, and involving, these complexes. As we have explored in this manuscript, changes in metal-metal bonding play a central role in determining the photochemical behavior of these species.

Metal carbonyl dimers represent perhaps the simplest of systems in which M-M bonding can be studied. The M$\mathrm{M}$ bonds of most metal carbonyl dimers can be readily cleaved via visible or ultraviolet excitation. In species containing bridging ligands, the bridging ligands may strongly influence the overall effect of the initial M-M bond cleavage step. The evidence to date suggests that $\mathrm{CO}$ bridging ligands undergo relatively facile cleavage, while a variety of other bridging ligands serve to more effectively tether the two "halves" of a cleaved M-M bond.

Metal carbonyl trimers and higher nuclearity clusters typically contain more bonds that need to be cleaved in order to generate long-lived M-M bond cleavage products. These include both the M-M bonds themselves as well as any bridging ligands that also serve to bond the cluster together. For this reason, ligand dissociation (e.g. CO-loss) pathways tend to compete quite efficiently with $\mathrm{M}-\mathrm{M}$ bond cleavage in these complexes in dictating the photochemistry observed on diffusion-limited time scales. The solvent may likely influence photofragementation of the cluster, or lack thereof, by dissipating the excess energy present shortly after photoexcitation. The only cluster which we have observed to fragment was $\mathrm{Fe}_{3}(\mathrm{CO})_{12}$, while no fragmentation of the metal skeleton was observed for any of the other clusters discussed in this manuscript. In the case of solution-phase photolysis of $\mathrm{Ru}_{3}(\mathrm{CO})_{12}$, multiple carbonyl ligands can be dissociated via a single pho- 
ton event, ${ }^{87,88}$ and the $\mathrm{Ru}_{3}$ backbone still does not fragment. It is believed that short-lived M-M cleavage transients are a common feature in the visible and/or UV photochemistry of virtually all metal carbonyl dimers and clusters, though the fact that these tend to recover on the sub-nanosecond time scale means that they do not tend to play any significant role in solution phase chemistry occurring on diffusion-limited time scales. As was discussed in section 4.5, the interpretation of genuine M-M bond cleavage transients as such (as opposed to interpretation of these same spectra as representing vibrationally excited parent complexes), with certainty, is not always a simple task, and careful examination of all available data can be both helpful and necessary to reach reliable conclusions in this regard.

We hope that the body of work reviewed in this manuscript serves to provide the reader with a reasonably thorough background on the primary photochemical processes associated with photochemical excitation of metal carbonyl dimers and clusters, such that some basic level of predictive insight into the photochemistry of related complexes may be established. Finally, we thank Albert F. Cotton for his numerous contributions to this field during his lifetime, and acknowledge that he and his coworkers laid the foundation for much of the work described in this manuscript.

\section{AUTHOR INFORMATION}

\section{Corresponding Author}

*E-mail: cbharris@berkeley.edu

\section{ACKNOWLEDGMENT}

This work was supported by NSF Grant CHE-1213135. Much of the work reviewed was also facilitated by use of the Molecular Graphics and Computation Facility at UC-Berkeley (Grants CHE-0840505, CHE-0233882) and/or resources of the National Energy Research Scientific Computing Center, which is supported by the Office of Science of the U.S. Department of Energy under Contract no. DE-AC02-05CH11231. J.P.L. acknowledges support through an NSF graduate research fellowship. Finally, the authors thank the numerous students of the Harris group who, over the years, have contributed to the studies described in this manuscript.

\section{REFERENCES}

(1) M.I. Bruce, D.F. Shriver, H.D. Kaesz, R.D. Adams, The Chemistry of Metal Cluster Complexes; Wiley-VCH: New York, 1990.

(2) R.D. Adams, F.A. Cotton, Catalysis by Di- and Polynuclear Metal Cluster Complexes; Wiley-VCH: New York, 1998.

(3) P.J. Dyson, S.J. McIndoe, Transition Metal Carbonyl Cluster Chemistry; Gordon and Breach: Amsterdam, 2000.

(4) J.A. Bertrand, F.A. Cotton, W.A. Dollase, J. Am. Chem. Soc. $85(1963) 1349$.

(5) M.J. Bennett, F.A. Cotton, R.A. Walton, J. Am. Chem. Soc. 88 (1966) 3866.

(6) F.A. Cotton, N.F. Curtis, C.B. Harris, B.F.G. Johnson, S.J. Lippard, J.T. Mague, W.R. Robinson, J.S. Wood, Science 145 (1964) 1305.

(7) F.A. Cotton, C.B. Harris, Inorg. Chem. 4 (1965) 330.

(8) F.A. Cotton, Inorg. Chem. 4 (1965) 334.
(9) F.A. Cotton, Acc. Chem. Res. 11 (1978) 225.

(10) T.J. Meyer, J.V. Caspar, Chem. Rev. 85 (1985) 187.

(11) J.C. Ford, J. Organomet. Chem. 383 (1990) 339.

(12) N.E. Leadbeater, J. Chem. Soc. Dalton Trans. (1995) 2923.

(13) P. Chini, J. Organomet. Chem. 200 (1980) 37.

(14) G.L. Geoffroy, M.S. Wrighton, Organometallic Photochemistry, Academic, New York, 1979.

(15) D.M. Roundhill, Photochemistry and Photophysics of Metal Complexes (Modern Inorganic Chemistry), Springer, New York, 1994.

(16) M. Wrighton, Chem. Rev. 74 (1974) 401.

(17) A. Hudson, M.F. Lappert, B.K. Nicholson, J. Chem. Soc., Dalton Trans. (1977) 551.

(18) M.S. Wrighton, D. Bredesen, J. Organomet. Chem. 50 (1973) C35.

(19) M.S. Wrighton, D.S. Ginley, J. Am. Chem. Soc. 97 (1975) 2065.

(20) M.S. Wrighton, D. S. Ginley, J. Am. Chem. Soc. 97 (1975) 4246.

(21) H. Yesaka, T. Kobayashi, K. Yasufuku, S. Nagakura, J. Am. Chem. Soc. 105 (1983) 6249.

(22) S.P. Church, M. Poliakoff, J.A. Timney, J.J. Turner, J. Am. Chem. Soc. 103 (1981) 7515.

(23) L.J. Rothberg, N.J. Cooper, K.S. Peters, V. Vaida, J. Am. Chem. Soc. 104 (1982) 3536.

(24) J.L., Hughey, C.P. Anderson, T.J. Meyer, J. Organomet. Chem. 125 (1977) C49.

(25) T. Ziegler, V. Tschinke, C. Ursenbach, J. Am. Chem. Soc. 109 (1987) 4825.

(26) A.W. Ehlers, G. Frenking, Organometallics 14 (1995) 423.

(27) A.K. Hughes, K. Wade, Coord. Chem. Rev. 197 (2000) 191.

(28) S.A. Trushin, W. Fuss, W.E. Schmid, K.L. Kompa, J. Phys. Chem. A 102 (1998) 4129.

(29) J. Franck, E. Rabinowitch, Trans. Faraday Soc. 30 (1934) 120.

(30) E. Rabinowitch, W.C. Wood, Trans. Faraday Soc. 32 (1936) 1381.

(31) E. Rabinowitch, Trans. Faraday Soc. 33 (1937) 122.

(32) D.A. Braden, E.E. Parrack, D.R. Tyler, Coord. Chem. Rev. 211 (2001) 279.

(33) K.J. Covert, E.F. Askew, J. Grunkemeier, T. Koenig, D.R. Tyler, J. Am. Chem. Soc. 114 (1992) 10446.

(34) B.E. Lindfors, J.L. Male, K.J. Covert, D.R. Tyler, Chem. Commun. (1997) 1687.

(35) J.L. Male, B.E. Lindfors, K.J. Covert, D.R. Tyler, J. Am. Chem. Soc. 120 (1998) 13176.

(36) H. Yang, P.T. Snee, K.T. Kotz, C.K. Payne, C.B. Harris, J. Am. Chem. Soc. 123 (2001) 4204.

(37) J.F. Cahoon, M.F. Kling, S. Schmatz, C.B. Harris, J. Am. Chem. Soc. 127 (2005) 12555.

(38) A.L. Harris, J.K. Brown, C.B. Harris, Ann. Rev. Phys. Chem. 39 (1988) 341.

(39) Also see the introduction of Ref. 32 and references therein.

(40) C.R. Baiz, R. McCanne, K.J. Kubarych, J. Am. Chem. Soc. 131 (2009) 13590.

(41) J.D. Harris, A.B. Oelkers, D.R. Tyler, J. Am. Chem. Soc. 129 (2007) 6255 .

(42) A.F. Hepp, M.S. Wrighton, J. Am. Chem. Soc. 105 (1983) 5934. (43) A.E. Stiegman, D.R. Tyler, J. Am. Chem. Soc. 104 (1982) 2944.

(44) A.E. Stiegman, D.R. Tyler, Coord. Chem. Rev. 63 (1985) 217.

(45) A.E. Stiegman, M. Stieglitz, D.R. Tyler, J. Am. Chem. Soc. $105(1983) 6032$.

(46) C.E. Philbin, A.S. Goldman, D.R. Tyler, Inorg. Chem. 25 (1986) 4434. 
(47) M.F. Kling, J.F. Cahoon, E.A. Glascoe, J.E. Shanoski, C.B. Harris, J. Am. Chem. Soc. 126 (2004) 11414.

(48) J.P. Lomont, S.C. Nguyen, C.B. Harris, J. Phys. Chem. A 117 (2013) 3777.

(49) J.P. Lomont, S.C. Nguyen, C.B. Harris, J. Phys. Chem. A, 117 (2013) 2317.

(50) J.F. Cahoon, M.F. Kling, K.R. Sawyer, H. Frei, C.B. Harris, J. Am. Chem. Soc. 128 (2006) 3152.

(51) A.R. Manning, J. Chem. Soc. A. (1968) 1319.

(52) P.A. McArdle, A.R. Manning, J. Chem. Soc. A (1969) 1948.

(53) J.G. Bullitt, F.A. Cotton, T.J. Marks, J. Am. Chem. Soc. 92 (1970) 2155 .

(54) O.A. Gansow, A.R. Burke, W.D. Vernon, J. Am. Chem. Soc. 98 (1976) 5817.

(55) M.W. George, T.P. Dougherty, E.J. Heilweil, J. Phys. Chem. 100 (1996) 201.

(56) J.N. Moore, P.A. Hansen, R.M. Hochstrasser, J. Am. Chem. Soc. 111 (1989) 4563.

(57) J.G. Bullitt, F.A. Cotton, T.J. Marks, Inorg. Chem. 11 (1972) 671.

(58) P. McArdle, A.R. Manning, J. Chem. Soc. A (1970) 2128.

(59) G.G. Sumner, H.P. Klug, L.E. Alexander, Acta. Crystallogr. 17 (1964) 732.

(60) P.C. Leung, P. Coppens, Acta Crystallogr. B39 (1983) 535.

(61) D. Braga, F. Grepioni, P. Sabatino, A. Gavezzotti, J. Chem. Soc. Dalton Trans. (1992) 1185.

(62) S. Moskovich, D. Reuvenov, R.H. Schultz, Chem. Phys. Lett. 431 (2006) 62.

(63) J.T. Bays, T.E. Bitterwolf, K.A. Lott, M.A. Ollino, A.J. Rest, L.M. Smith, J. Organomet. Chem. 554 (1998) 75.

(64) R.H. Summerville, R. Hoffman J. Am. Chem. Soc. 98 (1976) 7240.

(65) J.G. Norman, D.J. Gmur, J. Am. Chem. Soc. 99 (1977) 1446.

(66) P.E.M. Siegbahn, Theor. Chim. Acta 86 (1993) 219.

(67) J.A. Connor, Organometallics 1 (1982) 1166.

(68) S. Kaziannis, S. Santabarbara, J.A. Wright, G.M. Greetham, M. Towrie, A.W. Parker, C.J. Pickett, N.T. Hunt, J. Phys. Chem. B 114 (2010) 15370.

(69) J.L. Bingaman, C.L. Kohnhorst, G.A. Van Meter, B.A McElroy, E.A. Rakowski, B.W. Caplins, T.A. Gutowski, C.J. Stromberg, C.E. Webster, E.J. Heilweil, J. Phys. Chem. A 116 (2012) 7261.

(7o) N.M. Boyle, A.C. Coleman, C. Long, K.L. Ronayne, W.R. Browne, B.L. Feringa, M.T. Pryce, Inorg. Chem. 49 (2010) 10214.

(71) M.R. Harpham, S.C. Nguyen, Z. Hou, J.C. Grossman, C.B. Harris, M.W. Mara, A.B. Stickrath, Y. Kanai, A.M. Kolpak, D. Lee, D.-J. Liu, J.P. Lomont, K. Moth-Poulsen, N. Vinokurov, L.X. Chen, K.P.C. Vollhardt, Angew. Chem. Int. Ed. 51 (2012) 7692.

(72) Z. Hou, S.C. Nguyen, J.P. Lomont, C.B. Harris, N. Vinokurov, K.P.C. Vollhardt, Phys. Chem. Chem. Phys. 15 (2013) 7466.

(73) G.R. Dobson, R.K. Sheline, Inorg. Chem. 2 (1963) 1313.

(74) C.H. Wei and L.F. Dahl, J. Amer. Chem. Soc. 91 (1969) 1351.

(75) F.A. Cotton, J.M. Troup, J. Am. Chem. Soc. 96 (1974) 4155.

(76) F.A. Cotton, D.L. Hunter, Inorg. Chim. Acta 11 (1974) L9.

(77) J.P. Lomont, A.J. Shearer, S.C. Nguyen, C.B. Harris, Organometallics 32 (2013) 2178.

(78) P. Portius, J. Yang, X.-Z. Sun, D.C. Grills, P. Matousek, A.W. Parker, M. Towrie, M.W. George, J. Am. Chem. Soc. 126 (2004) 10713.

(79) S.C. Fletcher, M. Poliakoff, J.J. Turner, Inorg. Chem. 25 (1986) 3597.

(8o) N.J. Tro, J.C. King, C.B. Harris, Inorg. Chim. Acta 229 (1995) 469.

(81) M.R. Churchill, F.J. Hollander, J.P. Hustchinson, Inorg. Chem. 16 (1977) 2655.

(82) E. Hunstock, C. Mealli, M.J. Calhorda, J. Reinhold, Inorg. Chem. 38 (1999) 5053.
(83) E.A. Glascoe, M.F. Kling, J.E. Shanoski, C.B. Harris Organometallics 25 (2006) 775.

(84) M.F. Desrosiers, P.C. Ford, Organometallics 1 (1982) 1715.

(85) M.F. Desrosiers, D.A. Wink, P.C. Ford, Inorg. Chem. 24 (1985) 1.

(86) M.F. Desrosiers, D. Wink, R. Trautman, A.E. Friedman, P.C. Ford, J. Am. Chem. Soc. 108 (1986) 1917.

(87) Q. Kong, J.H. Lee, A. Plech, M. Wulff, H. Ihee, M.H.J. Koch, Angew. Chem. Int. Ed. 47 (2008) 5550.

(88) M.R. Harpham, A.B. Stickrath, X. Zhang, J. Huang, M.W. Mara, L.X. Chen, D.-J. Liu, J. Phys. Chem. A 117 (2013) 9807.

(89) P. Portius, J. Yang, X.-Z. Sun, D.C. Grills, P. Matousek, A.W. Parker, M. Towrie, M.W. George, J. Am. Chem. Soc. 126 (2004) 10713 .

(90) M. Besora, J.-L. Carreón-Macedo, A.J. Cowan, M.W. George, J.N. Harvey, P. Portius, K.L. Ronayne, X.-Z. Sun, M. Towrie, J. Am. Chem. Soc. 131 (2009) 3583.

(91) S.C. Nguyen, J.P. Lomont, M.C. Zoerb, A.D. Hill, J.P. Schlegel, C.B. Harris, Organometallics, 31 (2012) 3980.

(92) C.M. Brookes, J.P. Lomont, S.C. Nguyen, J.A. Calladine, X.-Z. Sun, C.B. Harris, M.W. George, Polyhedron (2014) In Press. DOI: 10.1016/j.poly.2013.12.028

(93) E.R. Corey, L.F. Dahl, Inorg. Chem. 1 (1962) 521.

(94) M. Poliakoff, J.J. Turner, Chem. Commun. (1970) 1008.

(95) J.G. Bentsen, M.S. Wrighton, J. Am. Chem. Soc. 109 (1987) 4518.

(96) E. Hunstock, C. Mealli, M.J. Calhorda, J. Reinhold, Inorg. Chem. 38 (1999) 5053.

(97) C.O. Quicksall, T.G. Spiro, Inorg. Chem. 7 (1968) 2365.

(98) H. Chen, Z.-C. Tang, R.-B. Huang, L.-S. Zheng, Eur. J. Mass Spectrom. 6, (2000) 19.

(99) T. Ziegler, V. Tschinke, C. Ursenbach, J. Am. Chem. Soc. 109 (1987) 4825.

(100) A.W. Ehlers, G. Frenking, Organometallics 14 (1995) 423.

(101) L.J. Farrugia, D. Braga, F. Grepioni, J. Organomet. Chem. 573 (1999) 6o.

(102) J.P. Lomont, S.C. Nguyen, C.B. Harris, Organometallics 31 (2012) 4031.

(103) F.A. Cotton, Inorg. Chem. 5 (1966) 1083.

(104) C.H. Wei, Inorg. Chem. 8 (1969) 2384.

(105) J. Evans, B.F.G. Johnson, J. Lewis, T.W. Matheson, J.R. Norton, J. Chem. Soc., Dalton Trans. (1978) 626.

(106) D.V. Krupenya, E.O. Danilov, M.A.J. Rodgers, S.P. Tunik, J. Phys. Chem. A 107 (2003) 8867.

(107) E.R. Corey, L.F. Dahl, W. Beck, J. Am. Chem. Soc. 85 (1963) 1202.

(108) S.P. Tunik, A.I. Yarmolenko, A.B. Nikol'skii, Inorg. Chim. Acta 205 (1993) 71.

(109) J.V. Caspar, T.J. Meyer, J. Am. Chem. Soc. 102 (1980) 7794. 
The primary photochemistry of transition metal dimers and clusters is reviewed with an emphasis on the changes in metal-metal bonding that take place immediately following photoexcitation. 


\section{A look at the primary photochemistry of metal-metal bonded complexes}
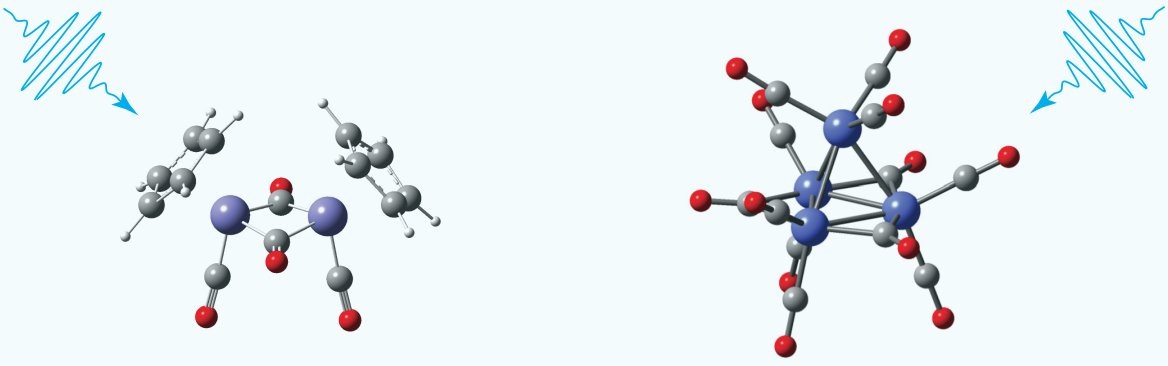